Aus der $\mathrm{k}, \mathrm{k}$. deutschen Universitäts-Augenklinik und dem $\mathrm{k} . \mathrm{k}$. dentschen hygienischen Institut in Prag.

\title{
Untersuchungen über die Biologie der Linse.
}

\author{
Von
}

Dr. Robert Salus,

I. Assistenten der Klinik.

Seit der Einführung des Begriffes der Autointoxikation in die moderne Pathologie durch Bouchard(1), seit den Arbeiten von v. Jaksch (2) über dieses Thema und der Aufstellung seines Systems der endogenen Toxikosen hat die Lehre von den Wirkungen der metabolischen, der im Körper selbst aus an sich ganz unschädlichen Stoffen entstehenden Gifte grosse Bedeutung für die Pathogenese der Krankheiten gewonnen und dies nicht nur in der inneren Medizin, sondern auch in andern Zweigen der Heilkunde.

So steht seit langem in der Ophthalmologie der Zusammenhang schwerer, durch Autointoxikation entstehender Stoffwechselanomalien, wie der harnsauren Diathese, des Diabetes, der Urämie mit Affektionen der Netzhaut, des Sehnerven und der Linse ausser Zweifel; so hat erst vor kurzer Zeit auf die Bedeutung dieser endogenen Giftwirkungen für die Ätiologie mancher Augenerkrankungen Elschnig(B) hingewiesen und auf Grund genauer klinischer Beobachtung und therapeutischer Erfolge die Entstehung vieler Iritiden, Cyclitiden, mancher Augenmuskellähmungen durch Autointoxikation, vorwiegend solche enterogener Art, im höchsten Grade wahrscheinlich gemacht.

Den bei solchen Erkrankungen im Organismus entstehenden Giften, deren Wirkungsweise meist wohl bekannt, wenn auch ihre chemische Zusammensetzung bis jetzt nur teilweise aufgeklärt ist, hat die moderne Biologie eine Reihe von neuen Stoffen hinzugefügt, deren Chemismus noch vollkommen ungeklärt, deren Bedeutung für die Pathogenese gewisser Affektionen aber nicht mehr zu leugnen ist.

Wie nach der Darstellung der Ptomaine, des Sepsins und Putrescins usw., sofort die Vermutung ausgesprochen wurde, dass diese 
Gifte, so wie sie ausserhalb des Körpers aus faulenden Stoffen entstehen, ebenso im lebenden Organismus selbst durch Stoffwechselstörungen, Eiweissfäulnis sich bilden, zur Resorption gelangen und dadurch Vergiftungen herbeiführen könnten, so wurde auch gleich nach der Entdeckung der Cytotoxine (Bämolysine), die an die Namen Bordet, Ehrlich, Morgenroth geknüpft ist, der Gedanke wach, dass solche, vorerst meist künstlich erzengte Stoffe gelegentlich auch endogen im lebenden Organismus selbst entstehend eine Autointoxikation hervorrufen könnten.

Wie stets bei der Auffindung so grundlegender Tatsachen, überflügelte auch hier die Spekulation die langsamere, exakte, experimentelle Forschung und bald wurde für eine ganze Reihe von Erkrankungen die Wahrscheinlichkeit eines solchen Zustandekommens angenommen. So hat man die Nephritis gravidarum, die Eklampsie durch im Körper der Schwangeren bei der Zerstörung von Placentarzellen entstehende Syncytiotoxine (W eichardt, Veit), viele chronische Nephritiden durch die Bildung von Autonephrolysinen (A scoli, Figari, Lindemann) za erklären gesucht; so wurden Autoovariolysine zur Erklärung der Chlorose (Lüdke) herbeigezogen usw. [citiert nach Fleischmann(4)].

Wenn wir jetzt, wo die erste Periode dieser durch die moderne Biologie in fast alle $Z$ weige der Medizin hineingetragenen neuen Anschauungen dem Ende nahe ist, das faktisch gewonnene Resultat in bezug auf die Klarlegung der Pathogenese der Erkrankungen überblicken, so bleibt - beim Menschen - eigentlich nur eine Affektion übrig, bei der mit Sicherheit solche Stoffe und zwar Autohämolysine nachgewiesen sind. Es ist dies die paroxysmale Hämoglobinurie.

Bei dieser wurden Stoffe im Blutserum nachgewiesen, die endogen entstehend die eigenen roten Blutkörperchen in der Kälte auflösten. [Landsteiner und Donath(5).] Aber auch hier wird von manchen Seiten unter Anführung schwerwiegender Gründe bezweifelt, ob diese Stoffe intravital wirksam sind und den hämoglobinurischen Anfall bedingen ${ }^{1}$.

Auch in die Augenheilkunde, ein Gebiet, auf dem so viele der wichtigsten Affektionen der pathogenetischen Forschung bisher unüberwindliche Hindernisse entgegengestellt haben, fanden die neven Anschauungen bald Eingang.

1) Wir verweisen auf die experimentelle und kritische Bearbeitung dieser Frage durch Hijmans van den Bergh. (Berliner klin. Wochenschr. Nr. 27. Juli 1909.) 
Golowin(6) war 1904 der erste, der den Gedanken aussprach, dass bei dem Zerfall von Zellen des Ciliarkörpers, bedingt durch eine Erkrankung, bzw. Verletzung desselben und bei dem Eintritt dieser Zerfallsprodukte in den Kreislauf, im Blute spezifische Zellgifte sich bilden könnten, welche im stande seien, den Ciliarkörper des andern Auges zu affizieren; und in der Tat gelang es Golowin, auf künstlichem Wege ein Cyclotoxin und ein Pigmentolysin darzustellen und so wenigstens prinzipiell die Möglichkeit einer solchen Giftwirkung darzutun. Durch dieselben Vorgänge, die ursprünglich vor allem für die Pathogenese der sympathischen Ophthalmie Geltung haben sollten, versuchte Golowin dann auch eine Reihe von andern Augenerkrankungen zu erklären, deren ätiologische Momente bis dahin noch nicht klar waren, für die aber eine bakterielle Entstehung auszuschliessen ist; so die Iritis serosa, einige Formen der Aderhautund Netzhautentzündung, manche Hornhautaffektionen; auch die Entstehung der senilen Katarakt sollte auf solche Ursachen zurückzuführen sein.

Ähnlich sind die Anschauungen, die Römer(7) seinen Arbeiten über die Pathogenese der senilen Katarakt zugrunde legt. Auch nach ihnen bildet eine Autointoxikation das ätiologische Moment.

Die Untersuchungen Römer's stehen derzeit im Mittelpunkt des Interesses, denn einerseits war hier - in der Ophthalmologie zum erstenmal - auf Grund systematischer biologischer Experimente der Versuch gemacht worden, die Möglichkeit eines Angriffspunktes solcher vorerst nur hypothetischer Autocytotoxine auf die Linse zu erweisen, insbesondere durch den Nachweis des Vorhandenseins ron A ufnahmsapparaten in derselben, der hypothetischen chemischen Körper, die den Sammelnamen Receptoren tragen; anderseits deswegen, weil diese Untersuchungen die Veranlassung zu originellen therapeutischen Versuchen gegeben haben, die freilich von vielen Seiten mit Widerspruch aufgenommen wurden, deren Wert oder Unwert aber bis jetzt unerwiesen ist.

Für das Verständnis des Nachfolgenden ist es unbedingt nötig, die Römersche Theorie an dieser Stelle genauer zu referieren:

Bei der regressiven Metamorphose des alternden Organismus findet beständig in reichem Masse Zerfall von Organzellen statt. Dureh Resorption dieses Zellmaterials können sich Autocytotoxine bilden. Dieselben werden aber nur unter zwei Bedingungen ihre Wirkung entfalten können. Nämlich erstens dann, wenn sie zu Zellen gelangen, die im stande sind, sie aufzunehmen, an sich zu binden. Solche Zellen müssen also auf die be- 
treffenden Cytotoxine passende Aufnahmsapparate, Receptoren im Sinne Ehrlichs besitzen.

Ist dies der Fall, hat die Linse in dev Tat derartige Aufnahmsapparate, so ist ein solches Einwirken der im Blute kreisenden Zellgifte auf das Linsenprotoplasma. prinzipiell möglich; ja, es müsste mit Sicherheit zu stande kommen, wenn nicht unter physiologischen Verhältnissen Regulationsvorrichtungen vorhanđen wären, welche die Verankerung an das gefährdete Organ zu verhindern im stande sind.

Durch die Untersuchungen WesseIys (8) war zuerst die Tatsache sicher gestellt worden; dass beim immunisierten Tiere die im Blute neugebildeten Agglutinine and Hämolysine unter normalen Umständen nicht in das Kammerwasser gelangen. Römer hat diese Versuche weiter fortgesetzt und auf Grund derselben das Gesetz der Oytotoxinretention durch die sekretorischen Apparate des Anges aufgestellt: "Alle Körper" von Amboceptorenbau mit zwei funktionell verschiedenen haptophoren Gruppen werden nnter physiologischen Verhältnissen nicht durch die Gefässwände und das Epithellager der Ciliarfortsätze durchgelassen. Dasselbe gilt für die wichtigen Bestandteile des intermediären Stoffwechsels, welche wir an ihrer fermentartigen Wirkung erkennen und mit Ehrlich als Komplemente bezeichnen. Es fehlen daher unter den Eiweisskörpern jedes normalen Kammerwassers die Receptoren dritter Ordnung und anch die anf sie eingestellten Komplemente."

Diese Retention als eine Funktion des Ciliarkörpers und seiner Epithelien hat natïrlich, wie für das Kammerwasser, auch für den Glaskörper - für diesen noch in viel höherem Grade - Geltung.

Wenn nun durch irgendeine Schädigung, besonders durch die regressive Metamorphose im Alter, der sekretorische Apparat des Ciliarkörpers dauernd gelitten hat, so treten die auf die Linse eingestellen, im Blute kreisenden Zellgifte in das Kammerwasser ïber und es kommt durch ihre Bindung an das Linsenprotoplasma zur Vergiftung desselben, deren Ausdruck die senile Katarakt ist.

Diese Theorie, durch zahlreiche Versuche gestützt, zahlreiche nengefundene Tatsachen durch streng logische Schlisse zu einem harmonischen Ganzen vereinigend, und entwickelt mit der ganzen Überzeugungskraft brillanter Dialektik, hat bis jetzt so gut wie nirgends Widerspruch geweckt; im Gegenteil wird, wie Römer in einer seiner letzten Arbeiten über dieses Thema bemerkt, die Zahl seiner Anhänger immer grösser; erst jüngst hat anch Golowin, indem er für diese Auffassung der Pathogenese des Altersstars die Priorität für sich in Anspruch nimmt, seine Übereinstimmung mit den Ansichten Römers kundgegeben. Freilich misst Römer selbst in seinen ersten den Altersstar betreffenden Arbeiten seiner Theorie nur heuristischen Wert bei. Ein solcher ist ihr gewiss nicht abzusprechen, denn wir verdanken seinen Untersuchungen die Feststellung einer Reihe hochinteressanter Tatsachen auf dem Gebiete der Physiologie und Pathologie des Auges in einer Richtung, die 
neue Bahnen für die ätiologische Forschung eröffnet, und die vor Römer so gut wie keiner eingeschlagen hatte.

Die Veranlassung zu den hier mitgeteilten Versuchen über denselben Gegenstand gab die Anregung meines verehrten Chefs, Herrn Professors Elschnig, zu untersuchen, ob man durch die modernen biologischen Methoden zu einem Urteil über die Wirkung oder den Wert der Lentokalintherapie Römers kommen könne. Ich möchte an dieser Stelle gleich erwähnen, dass die Untersuchungen zum Teil an der deutschen Augenklinik, zum Teil am hygienischen Institut in Prag ausgeführt wurden.

Betrachten wir zunächst die Frage, wie sie sich vom Standpunkt der Römerschen Hypothese darstellt, von der rein klinischen Seite, so ergibt sich aus dex supponierten Schädigung der Linse durch Toxine von aussen her die Notwendigkeit, nur die häufigste Form der senilen Katarakt, den subkapsulären Rindenstar als durch Wirkung der im Blute kreisenden Zellgifte entstanden aufzufassen; die andern Formen, die supranukleäre und intranukleäre müssen ätiologisch scharf gesondert werden und bleiben unerklärt.

Nun hatja auch Hess (9) die Möglichkeit wesentlicher ätiologischer Unterschiede zwischen diesen verschiedenen Gruppen des Altersstars "nicht ohne weiteres von der Hand weisen können". Hess kommt auf Grund seiner anatomischen Untersuchungen und der Berüclssichtigung der $\ddot{A}$ bnlichkeit des Beginnes vieler experimenteller Starformen mit dem beginmenden subkapsulären Rindenstar zur Ansicht, dass eine von aussen in die Linse eindringende Schädlichkeit zunächst die Epithelzellen der vorderen Kapsel zum Absterben bringt und dass durch deren Untergang die zur Linsentrübung führenden Vorgänge in den Rindenfasern eingeleitet werden.

Klinisch ist aber die Grenze zwischen den drei bzw. vier Altersstarformen (wenn wir die nach Hess nicht mehr unbedingt zum Altersstar gehörige Form der Cataracta punctata noch hierher zählen), die Hess unterscheidet, durchaus keine scharfe. Dass subkapsulärer Rindenstar mit Kernstar, supra* und intranukleärer Star häufig an einer Linse nebeneinander sich finden, führt Hess selbst an. Ganz gewöhnlich ist es in solchen Fällen, dass man bald mebr den einen, bald mehr den andern Trübungstypus hervortreten sieht, und nicht gar so selten kann man auch bei einem Patienten an dem einen Auge vorwiegend den einen, am andern Auge mehr den andern ausgeprägt finden.

Veränderungen des Kapselepithels hat Hess freilich vorwiegend 
beim subkapsulären Rindenstar, jedoch auch bei der punctata nachgewiesen; er gibt aber selbst an, dass sich solche Veränderungen auch bei den andern Altersstarformen, ja auch bei klinisch ganz normalen Linsen finden können (wenn auch für letztere die Frage offen gelassen wird, ob die Veränderungen nicht als Kunstprodukte aufzufassen sind).

Nicht ganz ungezwungen ist es auch, die hintere Corticalkatarakt, wie sie in sonst ganz normalen Augen entweder in Form von zentral gelegenen subkapsulären Herden, oder auch in Form von Speichen bei fast oder vollkommen klarer Vorderrinde oder geringen äquatoriellen Trübungen vorkommt, auf die Schädigung des Vorderkapselepithels zurückzuführen. Und trotzdem muss doch auch diese Altersstarform dem subkapsulären Star zugezählt werden.

Bei so vielfachen Übergängen zwischen diesen einzelnen Typen muss es doch wohl zweifelhaft bleiben, ob man berechtigt ist, für dieselben ätiologische Unterschiede anzunehmen.

Dieses Prinzip der ätiologischen Trennung vertritt aber Römer auf Grund seiner Theorie notwendigerweise noch viel schärfer als Hess.

Eine andere Schwierigkeit ergibt sich für Römer aus dem Umstande, dass man nur ungemein selten die senile Katarakt an beiden Augen in gleichem Stadium der Entwicklung sieht, ja oft an einem Auge einen überreifen Altersstar findet, während die Linse des andern nur eben noch sichtbare feinste Tröpfehen zeigt. Beispielsweise ergab die Durchsicht der Krankengeschichten von 200 unserer Altersstarkranken, dass nur bei acht derselben die Katarakt auf beiden Augen ungefähr das gleiche Stadium zeigte, in den übrigen 192 Fällen ganz ausgesprochene Unterschiede in dieser Hinsicht bestanden.

Ein solches Verhalten müsste offenbar nach $\mathrm{R} \ddot{\mathrm{m}} \mathrm{mer}$, wenn auch möglich, so doch zu den Ausnahmen zählen und das gleiche Stadium der Starreife für die Linsen beider Augen die Regel bilden. Dass im Ciliarkörper des einen Auges die Regulationsvorrichtungen früher versagen, als bei dem andern - so versucht Römer diesem Einwand zu begegnen -, ist gewiss leicht denkbar, aber dass eine solche ungleichmässige Etablierung senil-sklerotischer Vorgänge in jedem Auge zur Regel würde, ist doch wohl schwer anzunehmen, um so mehr, als erwiesenermassen Unterschiede in der Ausbildung der Arteriosklerose in den beiden Körperhälften ziemlich selten sind.

Freilich finden wir ähnliche zeitliche Unterschiede auch beim Glaukom, ohne sie derzeit anders erklären zu können, als durch die 
gleiche Annahme. Vollkommen unerklärt bleibt aber durch die Theorie Römers eine andere Tatsache, die freilich fast alle derzeit angenommenen Theorien nicht berïcksichtigen. Es ist dies die exquisite Erblichkeit des Altersstars und besonders der Umstand, dass sich in der Regel nur „die Linsentrïbung im allgemeinen, nicht aber auch die Form der Katarakt vererbt" [Groenouw (10)]. Es ist dies gewiss auch Hess gegeniiber, der geneigt ist̂́, eine ätiologische Trennung der einzelnen Startypen anzunehmen, ein wichtiger Finwand.

Wir gehen nunmehr zur Besprechung der Versuchsresultate Römers über.

Wenn Römer annimmt, dass im senilen Organismus durch Zellzerfall Antigene in Freiheit gesetzt werden, welche im stande sind, die Bildung spezifisch auf die Linse wirkender Antikörper zu veranlassen, so war es in Konsequenz dieser Annahme vor allem seine Aufgabe, Receptoren im Linsenprotoplasma nachzuweisen, die diese Zellgifte an sich zu verankern im stande sind. Die moderne Immunitätslehre unterscheidet drei Ordnungen von Receptoren ${ }^{1}$ ). Wir beginnen wie Römer mit den Receptoren zweiter Ordnung, charakterisiert durch die Erscheinungen der Agglutination und Präcipitation.

Römer hat gefunden, dass die Linse Agglutinine für Kaninchenblutkörperchen besitzt, die bei herabgesetzter Temperatur in Wirkung treten. Bei Brutschranktemperatur verschwindet die Agglutination nach kurzer Zeit. Die Fähigkeit zu agglutinieren kommt den Linsen aller darauf untersuchten Säugetiere, auch der des Menschen, zu, entsprechend der von Uhlenhuth gefundenen Tatsache, dass die Linsen aller höheren Säugetiere biologisch einander gleichwertig sind. Die Agglutination bezieht sich stets nur auf die Blutkörperchen des Kaninchens, alle andern Blutarten bleiben unbeeinflusst.

Bevor ich auf die von mir angestellten Versuche eingehe, seien einige Worte über die dabei geïbte Technik vorausgesehickt. Meist kamen Schweinslinsen zur Verwendung; die Augen wurden ganz frisch vom Schlachthaus gebracht, sofort die Linse dureh Lappensehnitt und Druck entbunden, wobei auf die Erhaltung der Kapsel kein Gewicht gelegt wurde. Die Linsen wurden in steriler Reibschale zerrieben und in einem bestimmten (bei den einzelnen Versuchen jedesmal angeführten) Quantum physiologiseher Koch-

1) Es würde den Rahmen dieser Arbeit weit überschreiten, wenn ich auf die grundlegenden Begriffe der Immunitätslehre genauer eingehen sollte. Das unbedingt Nötige für diejenigen, denen dieses Arbeitsgebiet fern liegt, hat sehon Römer in seiner citierten Arbeit kurz und klar dargestellt, so dass ich hier auf diese verweisen kann. 
salzlösung anfgeschwemmt. Die Lösung wurde durch einige Stunden bei Zimmertemperatur stehen gelassen, der Extrakt dann filtriert. Die sonstige Technik war die in der Immunitätslehre jetzt allgemein gebränchliche.

\section{Agglutinationsversuche.}

Drei Kalbslinsen in $15 \mathrm{cem} \mathrm{NoCl}$. Zu je $2 \mathrm{~cm}$ des Filtrates $1 \mathrm{ccm}$ einer $5 \%$ igen Lösung von zweimal gewaschenen Kaninchenblutkörperchen hinzugesetzt. - Im Eisschrank tritt nach kaum einer halben Stunde stärkste Agglutination ein, zu deren völliger Lösung ein Aufenthalt von wenigen Minuten bei $37^{\circ}$ genügt.

\begin{tabular}{c|c|c}
\hline $\begin{array}{c}\text { Schweinslinse 5 auf } \\
25 \mathrm{ccm} N a C l\end{array}$ & $\begin{array}{c}\text { Kaninchenblutkörperchen } \\
5 \%\end{array}$ & Agglutination bei $10^{\circ}$ \\
\hline $2 \mathrm{ccm}$ & $1 \mathrm{ccm}$ & +++ \\
$1 \%$ & $1 \%$ & +++ \\
NaOl $2 "$ & $1 \%$ & ++
\end{tabular}

\begin{tabular}{c|c|c}
\hline Schweinslinse 5:10 NaCl & $\begin{array}{c}\text { Meerschweinchenblut- } \\
\text { körperchen } 5 \%\end{array}$ & Agglutination bei $10^{\circ}$ \\
\hline NaCl $2 \mathrm{ccm}$ & $1 \mathrm{ccm}$ & $\theta$ \\
& $1 \%$ & $\theta$
\end{tabular}

\begin{tabular}{c|c|c}
\hline \hline Schweinslinse 5:10 NaCl & Rinderblutkörperchen 5\% & Agglutination bei $10^{\circ}$ \\
\hline \hline $2 \mathrm{NaCl} 2$, & $1 \mathrm{ccm}$ & $\theta$ \\
\hline
\end{tabular}

Ebenso werden alle andern von Römer untersuchten Blutarten von der Linsenlösung nicht agglutiniert.

\begin{tabular}{c|c|c}
\hline Schweinslinse 5: $25 \mathrm{NaCl}$ & $\begin{array}{c}\text { Kaninchenblutkörperchen } \\
5 \%\end{array}$ & Agglutination bei $37^{\circ}$ \\
\hline NaCl $2 \mathrm{ccm}$ & $1 \mathrm{ccm}$ & $\theta$ \\
\hline
\end{tabular}

Der Titer dieser Agglutination ist folgender (im Eisschrank nach Beobachtungsdauer von 24 Stunden):

\begin{tabular}{c|c|c}
\hline Schweinslinse 5:25 NaCl & Kaninchenblutkörperch. $5 \%$ & Resultat \\
\hline \hline 2,0 cen & $1 \mathrm{ccm}$ & +++ \\
1,0 " & $1 \%$ & +++ \\
0,5, & $1 \%$ & +++ \\
0,1, & $1 \%$ & ++ \\
0,05, & $1 \%$ & ++
\end{tabular}

จ. Graefe's Archiv für Ophthalmologie. LXXII. 3. 
Bei einem zweiten Versuch war er etwas geringer:

\begin{tabular}{c|c|c}
\hline Schweinslinse 5:25 NaCl & Kaninchenblutkörperch. 5\% & Agglutination \\
\hline \hline $1,0 \mathrm{ccm}$ & $1 \mathrm{ccm}$ & +++ \\
0,50, & $1 \%$ & +++ \\
0,1, & $1 \%$ & ++ \\
$0,05 \%$ & $1 \%$ & $\theta$ \\
$0,01 \%$ & $1 \%$ &
\end{tabular}

Bis hierher konnten unsere Versuche die Angaben Römers voll und ganz bestätigen; wie aus dem letztangeführten hervorgeht, wirkt die von uns angewendete Konzentration noch bis zu einer Dosis von 0,1 agglutinierend, so dass wir bei allen unsern Versuchen mit einem Agglutinationsüberschuss gearbeitet haben.

Römer betont, dass natürlich diesen Receptoren unter physiologischen Bedingungen nicht etwa die Aufgabe zukommt, Kaninchenblut zu agglutinieren, sondern dass wir in dieser Fähigkeit nur den Ausdruck für eine spezifisch chemische Energie bestimmter Gruppen des Linsenprotoplasmas zu erblicken haben. In diesem Sinne spricht also die ganz merkwürdige Beschränkung der Agglutination auf eine Blutart nicht gegen die Receptorennatur der in Frage stehenden Körper.

Auffallender dagegen erscheint schon die Unwirksamkeit der agglutinierenden Substanz bei Körpertemperatur; wenn auch speziell bei der Agglutination die Verhältnisse etwas anders liegen, als bei andern biologischen Reaktionen, und in gewissen Fällen Agglutination sowohl bei niedrigerer als auch bei höherer Temperatur vollständiger oder rascher exfolgt, als bei dem sonst in der Biologie geltenden Optimum von $37^{\circ}$, so muss doch das völlige Versagen dieser „Receptoren" bei Körpertemperatur Zweifel an ihrer echten Receptorennatur wachrufen.

Hier kann nur ein Versuch einen Beweis für dieselbe erbringen, der die Bindung der Blutkörperchen an das Agglutinin feststellt. Es ist dies der Ehrlichsche "Bindungsversuch".

Römer schildert den von ihm angestellten Bindungsversuch in folgender Weise: „Je $2 \mathrm{ccm}$ eines gut wirksamen Kalbsinsenfiltrates +1 Tropfen Kaninchenblut bleiben über Nacht im Eisschrank stehen, um eine maximale Agglutination zu erzielen; dann wird die Flüssigkeit abgehebert and der Blutklumpen mehrmals mit auf Eisschranktemperatur abgekühlter Kochsalzlösung gewaschen. Dabei zeigt sich schon, dass die roten Blutzellen sehr fest aneinanderhaften, also die spezifisch agglutinierende Substanz gebunden haben. müssen. Die letzte Waschflüssigkeit wird durch Zusatz frischen Blutes dar- 
auf geprüft, ob sie noch Agglutinin enthält. Die Röhrchen mit dem in frischer Kochsalzlösung aufgeschwemmten Blutklumpen kommen jetzt in den Thermostaten oder in ein auf $37^{\circ}$ eingestelltes Wasserbad. Jetzt erfolgt, besonders wenn man wiederholt umschüttelt, in kurzer Zeit die Lösung der Agglutination. Schweben die Blutzellen dann genau so unagglutiniert wie in einer Kontrollösung, so werden sie schnell abzentrifugiert. Die darüber stehende Flüssigkeit wird abgehoben und erhält einen neuen Zusatz von Blut, die Röhrchen kommen wieder in den Eisschrank. Hatten die agglutinierten roten Blutzellen eine agglutinierende Substanz gebunden, so war zu erwarten, dass bei der Lösung der Agglutination infolge der Temperaturerhöhung diese Substanz jetzt in der Flüssigkeit in freiem Zustande nachweisbar wird. Dieses trifft in der Tat zu":

Römers Bindungsversuch.

\begin{tabular}{c|c|c}
\hline $\begin{array}{c}\text { Bei Eisschranktemperat. in Lin- } \\
\text { seneiweiss agglutinierte Blut- } \\
\text { körperchen, abzentrifugiert in } \\
\text { frischer Kochsalzlösung }\end{array}$ & $\begin{array}{c}\text { Prüfmg des Sedimentes } \\
\text { anf Agglutination }\end{array}$ & $\begin{array}{c}\text { Prüfung des Abgusses } \\
\text { auf Agglutination }\end{array}$ \\
\hline \hline Nr.1 \\
, 2 & $\begin{array}{c}\text { Noch Andeutung } \\
\text { Keine Spur }\end{array}$ & $\begin{array}{c}\text { Deutliche Agglutination } \\
\text { Komplette " }\end{array}$
\end{tabular}

Diesem Versuche fehlt die Klarheit, die sonst die Versuche Römers auszeichnet. Er sagt, dass der Blutklumpen nach Eintritt der ersten Agglutination mehrmals mit eiskalter Kochsalzlösung gewaschen wird. Nun ist es bei einem Bindungsversuch offenbar unerlässlich, dass die Waschflüssigkeit überall hindringt, dass der agglutinierte Blutklumpen nicht nur an seiner Oberfläche mit derselben in Berührung kommt, sondern dass sie auch in sein Innerstes dringt. Dies ist nur möglich, wenn der Blutklumpen in der Waschflüssigkeit gründlich aufgeschüttelt und in so kleine Teilchen zerlegt wird, als es eben durch Aufschütteln möglich ist. Lassen wir aber den Blutklumpen unzerschüttelt, so genügt ein kleines zwischen den Blutzellen klebendes Quantum der agglutinierenden Substanz - der Titer der Agglutination ist $j a$, wie oben ersichtlich, ein verhältnismässig hoher -, um noch Agglutination hervorzubringen. Es ist ja eben das Kriterium der Bindung, wie sie dieser Versuch dartun soll, dass durch Schütteln oder sonstige mechanische Momente die Bindung nicht gelöst werden kann. Führten wir nun den Versuch genau in derselben Weise durch, wie ihn Römer angestellt hat, aber so, dass durch Schütteln bei oben aufgesetztem Finger möglichste Vertellung des agglutinierten Blutes im Röhrchen zu stande kam, so war das Resultat von dem Römers vollkommen verschieden. Zuerst will ich jedoch noch einen anders angestellten Bindungsversuch anf ühren. 


\begin{tabular}{c|c|c|c}
\hline $\begin{array}{c}\text { Schweinslinse } \\
5: 25\end{array}$ & $\begin{array}{c}\text { Kaninchenblutkör- } \\
\text { perchen } 5 \%\end{array}$ & \multicolumn{2}{|c}{ Agglutination bei } \\
\hline 2 & 1 & $10^{\circ}$ & $37^{\circ}$ \\
\hline $\operatorname{NaCl} 2$ & 1 & +++ & $\theta$ \\
2 & 1 & $\begin{array}{c}++ \\
\theta\end{array}$ & $\theta$
\end{tabular}

Nach zwei Stunden kamen die zwei in den Brutschrank gestellten Röhrchen in den Eisschrank, wo nach kürzester Zeit maximale Agglutination erfolgte. Die beiden andern Röhrchen wurden im Eisschrank belassen, bis stärkste Agglutination eingetreten war (ungefähr 2 Stunden); dann wurde bei einem derselben der Bodensatz kräftig anfgeschüttelt und das Röhrchen in den Eisschrank zurückgestellt. Nach kürzester Zeit wieder stärkste Agglutination. - Bei dem andern Röhrchen wurde Abguss und Bodensatz gesondert untersucht. Es wurde unter Eis rasch zentrifugiert, die über dem Sediment stehende Flüssigkeit abgegossen und mit einem Kubikeentimeter der Kaninchenblutkörperchenlösung versetzt. Im Eisschrank erfolgte wieder sehr rasch maximale Agglutination.

Das Sediment wurde eimmal mit eiskalter Kochsalzlösung gründlich aufgeschüttelt und gewaschen, dann wieder mit eiskalter Kochsalzlösung versetzt und in den Eisschrank gestellt. Nach einer Beobachtungsdauer von 24 Stunden zeigte sich keine Spur von Agglutination. Nun kam die Eprouvette, die den mit Kaninchenblutkörperchen frisch versetzten Abguss enthielt und in der wieder stärkste Agglutination sich gezeigt hatte, unter Eis in die Zentrifuge; wieder wurde Abguss und Sediment getrennt, erstere so wie früher mit frischen Kaninchenblutkörperchen versetzt und in den Eisschrank gestellt; auch jetzt wiederum zeigte sich sehr rasch starke Agglutination, und wir konnten denselben Vorgang noch dreimal wiederholen, obne dass eine merkliehe Abnahme der Agglutinationsfähigkeit zutage trat. Dagegen zeigte das Sediment auch dieses Röhrchens, in derselben Weise behandelt, keine Spur von Agglutination während einer Beobachtungsdauer von 24 Stunden.

Wir haben dann, um darzutun, dass wirklich die Unterlassung des Schüttelns beim Waschen, von der oben die Rede war, der Grund für den Gegensatz in den Resultaten Römers und den unsern ist, beide Versuche, den einen so, wie ihn Römer angibt, den andern unter gründlichem Aufschütteln des Blutklumpens parallel angestellt:

Acht Röhrchen mit je $2 \mathrm{ecm}$ Schweinslinsenextrakt und einem Tropfen Kaninchenblatkörperchen kam über Nacht in den Eisschrank. Nach dieser Zeit war maximale Aggglutination eingetreten, Je zwei Röhrehen (wir bezeichnen die so behandelten Röhrchen mit $A$ ) wurden mit eiskalter Kochsalzlösung dreimal unter einfachem leichten Urnschütteln gewaschen. Je zwei andere Röhrchen $(B)$ wurden mit eiskalter Kochsalzlösung dreimal unter gründlichem Aufschütteln gewaschen. Ein Röhrchen $\mathcal{A}$ und ein Röhrchen $B$ wurden wieder in den Eisschrank gestellt; in dem Röhrchen $A$ trat in einer halben Stunde komplette Reagglutination ein, in dem Röhrchen $B$ 
war auch nach 24 Stunden keine Spur von Agglutination sichtbar. Es war also in $B$ die agglutinierende Substanz durch einfaches gründliches Wasehen vollkommen entfernt worden, eine Bindung hatte nicht stattgefunden. Bei $\mathcal{A}$ war hingegen das Waschen nicht im stande gewesen, das Agglutinin zu entfernen, weil offenbar der Blutklumpen nur an seiner Oberfläche gewaschen wurde, in seinem Innern die die Blutkörperchen aneinander klebende Masse unberührt blieb. Zwei Röhrchen von $A$ (beim Waschen einfach umgeschüttelt) und zwei Röhrchen von $B$ (gründlich aufgesehüttelt) wurden jetzt nach Entfernung der letzten Waschflüssigkeit mit frischer Kochsalzlösung versetzt und kamen in den Brutschrank. Hier zeigte sich schon in allerkürzester Zeit die Agglutination in $B$ vollkommen gelöst, während in $A$ zur kompletten Lösung ungefähr eine Viertelstunde nötig war. Die Blutkörperchen wurden dann in allen Röhrchen abzentrifugiert, der Bodensatz $(R)$ mit $1 \mathrm{ccm}$ Kochsalzlösung, die darüber stehende Flüssigkeit $(F)$ mit einem Tropfen Kaninchenblutkörperchen versetzt.

Nach einem Aufenthalt von 24 Stunden im Eisschranke ergab sich:

$$
\begin{aligned}
& \text { Agglutination }
\end{aligned}
$$

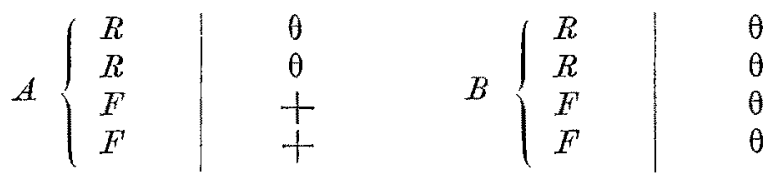

Tch habe deswegen diese Versuche genau beschrieben, weil ich mir wohl bewusst bin, von welcher prinzipiellen Wichtigkeit sie sind; denn der Nachweis, dass es sich hier nicht um eine echte Agglutination handelt, legt die erste Bresche in die scheinbar so festgegründete Lehre vom Receptorenaufban des Linsenprotoplasmas. Daher wird es nicht überfüssig sein, zu bemerken, dass gerade diese Versuche oft und oft wiederholt wurden, stets mit demselben eindeutigen Resultat: Die agglutinierende Substanz der Linse ist nicht im stande, durch wirkliche Bindung Kaninchenblutkörperchen zu verklumpen.

Danait sind aber alle Gründe, die Römer für die Receptorengrundlage dieser Agglutination anführt, gegenstandslos geworden. Gewiss handelt es sich auch hier nicht um ein rein physikalisches Phänomen, auch hier dürften chemische Vorgänge eine Rolle spielen, nur sind dieselben ganz andere, als diejenigen, welche die Immunitätslehre fordert, um eine Receptorenwirkung anzunebmen.

Denn hior fehlt vor allem das Kardinalsymptom derselben, die Bindung, eine Tlatsache, die von uns in zweifacher Weise nachgewiesen wurde; einmal dadurch, dass in den Blutkörperchen, auf welche die agglutinierende Substanz der Linse eingewirkt hatte, nach 
einfachem Waschen keine Reagglutination mehr auftrat, anderseits dadurch, dass dieses Agglutinin sich durch Behandlung mit Blutkörperchen fast gar nicht erschöpfen liess. Dies aber gelingt bei sperifischen Agglutininen bekanntlich sehr leicht.

Es erimnert dieser Vorgang an die Wirkungen nicht spezifischer agglutinierender Substanzen gegenüber Bakterien. So konnte Weil(11) an der Gelatine zeigen, dass dieselbe zwar auf den Receptorenapparat der Bakterien einwirkt (auf die haptophore und agglutinierbare Substanz), dass die Gelatine selbst jedoch nicht ähnliche Stoffe enthalte, wie agglutinierende Sera.

Auch bei den Versuchen mit der Gelatine gelang die Reagglutination nicht und die Erschöpfung der agglutinierenden Substanz nur ungemein schwierig.

Es wäre sicherlich nicht uninteressant, auch das Linsenagglutinin eingehender auf diese Eigenschaften zu untersuchen.

Übrigens ist auch die Eigenschaft der Linsensubstanz, bei bestimmter Temperatur Blutkörperchen und zwar nur eine bestimmte Art zu agglutinieren, auch sonst bei nicht spezifischen Agglutinationsvorgängen schon beobachtet. Ganz ähnlich zum Beispiel ist die Agglutination gewisser Arten von Blutkörperchen durch Rohrzucker-, Mannit-Alanitlösungen, wie sie zuerst Gürber gefunden, nach ihm Ivar Bang(12) genauer untersucht hat. Nach Bang agglutiniert Rohrzucker, in destilliertem Wasser gelöst, Ochsenblutkörperchen bei Brutschranktemperatur sehr stark; diese Agglutination verschwindet nach ungefähr zehnstündiger Aufbewahrung im Eisschrank. Blutkörperchen vom Kalb dagegen werden unter denselben Bedingungen nicht agglutiniert und es bedarf zuvor gewisser Vorbehandlung derselben, auf die an dieser Stelle nicht weiter einzugehen ist, um auch hier Agglutination zu erzielen.

Es sind dies also ganz ähnliche Eigenschaften, wie sie die Linse aufweist, und es berechtigt demnach die Beschränkung der Agglutination auf eine Blutkörperchenart nicht, chemische Vorgänge im Sinne einer echten Agglutination anzunehmen. Denn wahrscheinlich beruhen diese Vorgänge hier nur zum Teil auf Eigenschaften des Linsenprotoplasmas, zum Teil gewiss aber auch auf Besonderheiten der Blutkörperchen des Kaninchens.

Einen weiteren Nachweis für die Receptorennatur dieser Agglutinine sucht Römer durch den Nachweis der cymophoren Gruppe zu erbringen. Wir wissen, dass die cymophoren Gruppen der Antikörper gegenüber den haptophoren eine viel geringere Resistenz be- 
sitzen und dass sie speziell durch höhere Temperaturen rasch zerstört werden.

Um nun zu zeigen, dass dieses Gesetz auch für das LinsenAgglutinin Geltung hat, stellt Römer folgenden Versuch an:

„Je $2 \mathrm{cem}$ Linsenfiltrat wird fünf Minuten lang anf $60^{\circ}, 65^{\circ}, 70^{\circ}$, $80^{\circ}, 90^{\circ}, 100^{\circ}$ erwärmt; in den Röhrchen, in denen das Eiweiss ausgefällt war, wird der Bodensatz dureh die Zentrifuge von der Flüssigkeit getrennt, nach Aufsehwemmung der koagulierten Masse in Kochsalzlösung Kaninchenblut zugesetzt:

Römers Versuch zum Nachweis der cymophoren Gruppe:

\begin{tabular}{c|c|c}
\hline Temperatur & Flüssigleit (Agglutination) & Bodensatz \\
\hline $60^{\circ}$ & +++ & \\
$65^{\circ}$ & $+\frac{1}{+}+$ & \\
$70^{\circ}$ & deutlich & \\
$80^{\circ}$ & $\theta$ & $\theta$ \\
$90^{\circ}$ & $\theta$ & $\theta$ \\
$100^{\circ}$ & $\theta$ & $\theta$
\end{tabular}

Ich muss gestehen, dass mir dieser Versuch nicht verständlich ist. Erhitzt man eine Linseneiweisslösung - auch in noch so starker Verdünnung - auf ungefähr $80^{\circ}$, so tritt sofort vollständige Koagulation ein. Dass dann keine Agglutination mehr auftritt, ist nicht verwunderlich, ist aber gewiss nicht auf die Zerstörung der eventuell vorhandenen cymophoren Gruppen allein zu beziehen; denn dass koaguliertes Eiweiss, eine ausgefällte Masse, für biologische Reaktionen in der Regel untanglich ist, kann wohl nicht zweifelhaft sein.

Nach all dem Gesagten kommen wir also zu dem Schluss, dass wir keine Berechtigung haben, das Vorhandensein von Receptoren zweiter Ordnung in der Linse anzunehmen.

\section{Receptoren erster Ordnung in der Linse.}

Die Linse besitzt, wie Römer gefunden hat, die Fähigkeit, Tetanolysin zu binden; diesem, einer Komponente des Tetanusgiftes, kommt die Eigenschaft zu, rote Blutkörperchen aufzulösen. Lässt man nun Linsensubstanz und das Lysin durch einige Zeit, mindestens fünf Minuten, aufeinander einwirken und setzt jetzt rote Blutkörperchen hinzu, so bleibt die Auflösung derselben aus. Andere Gifte werden, wie Römer feststellt, durch die Linsensubstanz nicht gebunden. Ich setze einen der darauf bezüglichen Versuche Römers hierher: 


\begin{tabular}{|c|c|c|}
\hline \multicolumn{2}{|c|}{$\begin{array}{l}\text { Nach } 1 / 2 \text { Stunde Aufenthalt bei } 37^{\circ} \text { Zusatz von } \\
\text { Kaninchenblut }\end{array}$} & \\
\hline Linsenfiltrat & Toxindosis & \\
\hline $\begin{array}{l}3 \text { ccm } \\
2,5 " \\
2,0 " \\
1,5 " \\
1,0 " \\
0,9 " \\
0,8 " \\
0,7 " \\
0,6 " \\
0,5 " \\
0,4 " \\
0,3 " \\
0,2 " \\
0,1 "\end{array}$ & $\begin{array}{l}0,05 \\
0,05 \\
0,05 \\
0,05 \\
0,05 \\
0,05 \\
0,05 \\
0,05 \\
0,05 \\
0,05 \\
0,05 \\
0,05 \\
0,05 \\
0,05\end{array}$ & $\begin{array}{c}\text { Keine Spur von Lösung } \\
", \\
\text { Spürehen } \\
\text { Spur } \\
\text { teilweise } \\
\text { fast komplett } \\
" \\
" \\
\text { komplett } \\
" \\
" \\
"\end{array}$ \\
\hline
\end{tabular}

Unsere darauf bezüglichen Versuche waren kompliziert durch den Umstand, dass es uns lange nicht gelingen wollte, ein gut lösendes Tetanolysin zu bekommen. Es ist ja bekannt, dass sein Vorkommen im Tetanusgifte sehr variabel ist. Schliesslich war es uns doch möglich, durch die Güte des Herrn Dr. Přibram vom k. k. serotherapeutischen Institut in Wien ein brauchbares Lysin zu erhalten. Freilich war seine lösende Kraft nur gering und erreichte lange nicht die des Lysins, das Römer zur Verfügung gestanden war und das noch in einer Menge von 0,008 in 1\% iger Lösung wirksam war. Nichtsdestoweniger sind unsere Versuche doch vollkommen eindeutig und beweisend.

Es ist bekannt, dass die vor langem schon festgestellte Tatsache der grossen Affinität des Zentral-Nervensystems zum Tetanusgifte zur Annahme einer Receptorenwirkung Anlass gab (Wassermann und Takaki). Es hat sich aber später gezeigt, dass diese Eigenschaft hauptsächlich den fettartigen Bestandteilen der nervösen Organe zuzuschreiben ist, und dass die Stärke der bindenden Kraft des Gehirnes im Vergleich zu andern Organen auf dem weitaus grösseren Gehalt desselben an Lipoiden beruht.

Eine solche Ansicht hat erst kürzlich Landsteiner(13) ausgesprochen. Wenn auch nach diesem Autor die isolierten Lipoide nicht die Wirkung der gesamten Gehirnsubstanz erreichen, so hält er es doch für wahrscheinlich, dass sie in der Gesamtheit - etwa als Lipoideiweissverbindungen - eine stärkere Bindungsfähigkeit besitzen.

In der Voraussicht, dass diese Überlegungen auch für die Bin- 
dung des Lysins an die Linsensubstanz zutreffen wïrden, haben wir folgenden Versuch angestellt:

16 Schweinslinsen wurden zerrieben und aus ihnen - auf eine Linse $3 \mathrm{ccm}$ Kochsalzlösung gerechnet - eine Emulsion hergestellt.

$\mathrm{Zu} 16$ andern zerriebenen Schweinslinsen wurde $16 \times 3 \mathrm{ccm}$ Alkohol $\left(96^{\circ} \%_{0} \mathrm{ig}\right)$ zugesetzt, die Mischnng vier Stunden auf $60^{\circ}$ erwärmt, dann das gefällte Eiweiss durch Filtrieren entfernt und aus dem Filtrat der Alkolıol im Wasserbade bei $60^{\circ}$ verjagt. Der Rückstand wurde in $40 \mathrm{ccm} \mathrm{NaCl}$ emulgiert.

Das Tetanolysin, das uns in Trockensubstanz zur Verfügung stand, verwendeten wir in frisch hergestellter dünner Lösung, von der gerade noch 0,5 einen Kubikcentimeter $5 \%$ iger Blutkörperchenaufschwemmung in zwei Stunden komplett lösten.

Es wurde nun zu je zwei Teilen Linsenemulsion, zwei Teilen des Alkoholextraktes, zwei Teilen $\mathrm{NaCl}$, je ein Teil Tetanolysin hinzugesetzt und die Mischungen durch eine Stunde im Brutschrank aufbewahrt. Nach dieser Zeit erfolgte Zusatz von $1 \mathrm{ccm}$ einer $5 \%$ igen Lösung von Kaninchenblutkörperchen. Es ergab sich nun:

\begin{tabular}{|c|c|c|c|}
\hline \multicolumn{2}{|c|}{$\begin{array}{l}2 \mathrm{~T} \text {. Linsenemulsion } \\
+1 \mathrm{~T} \text {. Tetanolysin }\end{array}$} & $\begin{array}{l}2 \mathrm{~T} \text {. Alkoholextrakt } \\
+\mathrm{IT} \text {. Tetanolysin }\end{array}$ & $\begin{array}{c}2 \mathrm{NaCl}+ \\
1 \text { Tetanolysin }\end{array}$ \\
\hline $\begin{array}{ll}3 & \mathrm{ccm} \\
2 & " \\
1 & " \\
0,5 & " \\
0,1 & ,\end{array}$ & $\begin{array}{c}\text { starke Lösung } \\
\text { schwach } \\
\text { Spur } \\
\theta \\
\theta\end{array}$ & $\begin{array}{c}\text { schwache Lösung } \\
\theta \\
\theta \\
\theta \\
\theta\end{array}$ & $\begin{array}{c}\text { komplett } \\
\text { stark } \\
\text { Spur } \\
\theta\end{array}$ \\
\hline
\end{tabular}

Dieser Versuch ergibt also rollkommen klar, dass die Bindung des Tetanolysins im alkoholischen Extrakt stärker ausgesprochen ist, als im wässrigen. Da jedcch in der wässrigen Linsenemulsion fast die gesamte Substanz wirksam ist, während im alkoholischen Extrakt die ausgefällten Eiweisskörper durch Filtration entfernt wurden, so kann man die Behauptung aufstellen, dass es mit grösster Wahrscheinlichkeit auch in der wässrigen Linsenaufschwemmung die alkohollöslichen Bestandteile der Linsensubstanz sind, die die Tetanolysinbindung veranlassen.

Wir glauben also durch unsere Versuchsanordnung gezeigt zu haben, dass diese Bindung nichts anderes ist, als die längst bekannte Eigentümlichkeit alkohollöslicher Stoffe, die in der Linse in nicht geringer Menge vorkommen.

Vom Standpunkte Römers aus, der den Receptoren Eiweissnatur zuschreibt, können wir demnach bei diesem Phänomen von einer Receptorenwirkung nicht sprechen. 


\section{Komplementophile Receptoren in der Linse.}

Da der Angriff der Cytotoxine, bzw. Hämolysine mur durch Vermittlung der Komplemente des Serums ermöglicht wird, so war es für Römer von grosser Bedeutung, Gruppen in der Linse nachweisen zu können, welche die Fähigkeit haben, das Komplement an sich zu verankern. Römer fand vorerst, dass die Linse die Fähigkeit hat, die hämolytischen Eigenschaften des menschlichen Serums für Kaninchenblutkörperchen zu hemmen.

Römers Versuch.

\begin{tabular}{c|c|c|c}
\hline \hline Linsenfiltrat & Menschenserum & Kaninchenblut & Hämolyse \\
\hline $2 \mathrm{ccm}$ & 0,1 & 0,02 & $\theta$ \\
1 & 0,1 & 0,02 & $\theta$ \\
$0,5 \%$ & 0,1 & 0,02 & ganz minimale \\
$0,1 "$ & 0,1 & 0,02 & komplett
\end{tabular}

Durch eine grosse Anzahl von Versuchen und vollkommen einwandsfrei weist Römer ferner nach, dass die Hemimung der hämolytischen Wirkung des Serums auf bestimmte Blutarten auf der Verankerung des Komplementes durch das Linseneiweiss beruht. Aus diesem Umstande und gestützt auf die Tatsache, dass bei gewissen Komplementen diese Bindung ausbleibt, dass es sich demnach hierbei um spezifische Vorgänge handeln müsse, erschliesst Römer das Vorhandensein von Receptoren dritter Ordnung in der Linse.

Diese Versuchsergebnisse können aber eine wirklich spezifische Bindung nicht beweisen; diese Vorgänge stellen nichts anderes dar, als die nicht spezifische Komponente der Komplementverankerung, wie sie vielen Eiweisskörpern (z. B. Peptonen), ferner Lipoiden, Bakterien-Extrakten usw. zukommt.

Dass es sich hier tatsächlich um keine spezifische Eigenschaft der Linsensubstanz handelt, beweisen klar die folgenden von uns angestellten Versuche.

Linsenextrakt: Kalbslinsen, auf jede $5 \mathrm{cem} N a C l$, kommen mit Zusatz von aktivem Menschenserum (ebenso bei Zimmertemperatur hergestellte Extrakte aus frischen menschlichen Organen) auf $1 / 2$ Stunde in den Brutschrank; dann Zusatz von $1 \mathrm{cem}$ einer $5 \%$ Kaninchenblutkörperehenaufsehwemmung:

\begin{tabular}{c|c|c}
\hline Linse & $\begin{array}{c}\text { aktives Menschen- } \\
\text { serum }\end{array}$ & Hâmolyse \\
\hline $2 \mathrm{ccm}$ & 0,2 & $\begin{array}{c}\text { komplett } \\
\theta\end{array}$ \\
\hline
\end{tabular}




\begin{tabular}{|c|c|c|}
\hline & $\begin{array}{l}\text { aktives Menschen- } \\
\text { serum }\end{array}$ & Hämolyse \\
\hline $\begin{array}{l}\text { Milz } \\
2 \mathrm{ccm} \\
2 \quad,\end{array}$ & $\begin{array}{l}0,2 \\
0,1\end{array}$ & $\begin{array}{c}\text { komplett } \\
\theta\end{array}$ \\
\hline $\begin{array}{l}\text { Leber } \\
2 \mathrm{ccm} \\
2,\end{array}$ & $\begin{array}{l}0,2 \\
0,1\end{array}$ & $\begin{array}{c}\text { komplett } \\
,\end{array}$ \\
\hline $\begin{array}{l}\text { Niere } \\
2 \mathrm{ccm} \\
2, "\end{array}$ & $\begin{array}{l}0,2 \\
0,1\end{array}$ & $\begin{array}{c}\text { komplett } \\
\theta\end{array}$ \\
\hline
\end{tabular}

Zwei frische klare menschliche Linsen (aus dem Kadaver) in $8 \mathrm{ccm}$ $\mathrm{NaCl}$. Schüttelextrakt aus frischer, menschlicher Niere, Lunge, Gehim. Sonst wie im vorstehenden Versuch.

\begin{tabular}{|c|c|c|}
\hline & aktives Serum & Hämolyse \\
\hline $\begin{array}{l}\text { Linse } \\
2 \mathrm{ccm} \\
2 \% \\
2 \%\end{array}$ & $\begin{array}{l}0,2 \\
0,1 \\
-\end{array}$ & $\begin{array}{c}\text { Spur } \\
\theta \\
\theta\end{array}$ \\
\hline $\begin{array}{l}\text { Niere } \\
2 \mathrm{ccm} \\
2 \% \\
2 "\end{array}$ & $\begin{array}{l}0,2 \\
0,1 \\
-\end{array}$ & $\begin{array}{l}\text { komplett } \\
\text { fast komplett } \\
\qquad\end{array}$ \\
\hline $\begin{array}{l}\text { Lunge } \\
2 \mathrm{ccm} \\
2 " \\
2 "\end{array}$ & $\begin{array}{l}0,2 \\
0,1 \\
-\end{array}$ & $\begin{array}{l}\theta \\
\theta \\
\theta\end{array}$ \\
\hline $\begin{array}{l}\text { Gehirn } \\
2 \mathrm{ccm} \\
2 " \\
2 "\end{array}$ & $\begin{array}{l}0,2 \\
0,1 \\
-\end{array}$ & $\begin{array}{c}\text { komplett } \\
\theta \\
\theta\end{array}$ \\
\hline $\begin{array}{l}\text { Kontrolle } \\
\mathrm{NaCl} 2 \mathrm{ccm} \\
2 \%\end{array}$ & $\begin{array}{l}0,2 \\
0,1\end{array}$ & $\begin{array}{c}\text { komplett } \\
\text { stark }\end{array}$ \\
\hline
\end{tabular}

Bei diesen Versuchen ist zu berïcksichtigen, dass der Linsenextrakt viel leichter und konzentrierter herzustellen ist, als Organextrakte, bei denen oft die schwer vermeidliche Blutbeimengung störend wirkt.

Am deutlichsten zeigt der folgende Versuch, dass solche komplementophile Gruppen für die Linse nicht spezifisch sind:

$$
\left.\begin{array}{l}
2 \mathrm{~g} \text { Kalbslunge } \\
2 \mathrm{~g} \text { Kalbshirn } \\
2 \mathrm{~g} \text { Kalbsmilz } \\
2 \mathrm{~g} \text { Kalbsnieren } \\
2 \mathrm{extrahierte} \mathrm{Starkerne} \\
2 \mathrm{Schw} \text { einslinsen } \\
2 \text { klare Menschenlinsen }
\end{array}\right\} \text { in je } 10 \mathrm{ccm} \mathrm{NaCl} \text {. }
$$




\begin{tabular}{|c|c|c|c|}
\hline & $\begin{array}{l}\text { aktives Menschen- } \\
\text { serum }\end{array}$ & Kaninchenblut $5 \%$ & Hämolyse \\
\hline $\begin{array}{l}\text { Kalbslinse } \\
2 \mathrm{ccm} \\
2 \% \\
2 " \\
\end{array}$ & $\begin{array}{l}0,2 \mathrm{ccm} \\
0,1,3 \\
\end{array}$ & $\begin{array}{l}1 \mathrm{ccm} \\
1 " \\
1 "\end{array}$ & $\begin{array}{l}\theta \\
\theta \\
\theta \\
\end{array}$ \\
\hline $\begin{array}{l}\text { Hirn } \\
2 \mathrm{ccm} \\
2 " \\
2 "\end{array}$ & $\begin{array}{l}0,2 \mathrm{ccm} \\
0,1 \\
-\end{array}$ & $\begin{array}{l}1 \mathrm{~cm} \\
1 " n \\
1 "\end{array}$ & $\begin{array}{l}\theta \\
\theta \\
\theta \\
\end{array}$ \\
\hline $\begin{array}{l}\text { Niere } \\
2 \mathrm{ccm} \\
2 \% \\
2 "\end{array}$ & $\begin{array}{l}0,2 \mathrm{cmn} \\
0,1 \quad\end{array}$ & $\begin{array}{l}1 \mathrm{ccm} \\
1 \% \\
1 \% \\
\end{array}$ & $\begin{array}{l}\theta \\
\theta \\
\theta\end{array}$ \\
\hline $\begin{array}{l}\text { Milz } \\
2 \text { cem } \\
2 " \\
2 "\end{array}$ & $\begin{array}{c}0,2 \mathrm{ccm} \\
0,1, \\
\end{array}$ & $\begin{array}{l}1 \text { ccm } \\
1 \% \\
1 \%\end{array}$ & $\begin{array}{l}\theta \\
\theta \\
\theta\end{array}$ \\
\hline $\begin{array}{l}\text { Lunge } \\
2 \mathrm{ccm} \\
2 " \\
2 "\end{array}$ & $\begin{array}{l}0,2 \mathrm{cem} \\
0,1 \quad " \\
\end{array}$ & $\begin{array}{l}1 \mathrm{cem} \\
1 " \\
1 "\end{array}$ & $\begin{array}{c}\text { komplett } \\
\theta \\
\theta\end{array}$ \\
\hline $\begin{array}{c}\text { Schweinslinse } \\
2 \mathrm{ccm} \\
2 \% \\
2 \% \\
\end{array}$ & $\begin{array}{l}0,2 \mathrm{cem} \\
0,1, \\
-\end{array}$ & $\begin{array}{l}1 \mathrm{cem} \\
1 \% \\
1 "\end{array}$ & $\begin{array}{c}\text { komplett } \\
\theta \\
\theta \\
\end{array}$ \\
\hline $\begin{array}{c}\text { Menschenlinse } \\
2 \mathrm{ccm} \\
2 " \\
2 " \\
\end{array}$ & $\begin{array}{c}0,2 \mathrm{~cm} \\
0,1 \quad " \\
\end{array}$ & $\begin{array}{l}1 \mathrm{ccm} \\
1 " n \\
1 "\end{array}$ & $\begin{array}{l}\theta \\
\theta \\
\theta \\
\end{array}$ \\
\hline $\begin{array}{c}\text { Katarakt } \\
2 \text { ccm } \\
2 " \\
2 " \\
\end{array}$ & $\begin{array}{l}0,2 \mathrm{cem} \\
0.1 \ldots " \\
\end{array}$ & $\begin{array}{l}1 \mathrm{cem} \\
1 ", \\
1 "\end{array}$ & $\begin{array}{c}\text { komplett } \\
\theta \\
\theta \\
\end{array}$ \\
\hline $\begin{array}{c}\text { Kontrolle } \\
\mathrm{NaCl} 2 \mathrm{ccm} \\
2 "\end{array}$ & $\begin{array}{l}0,2 \mathrm{ccm} \\
0,1\end{array}$ & $\begin{array}{l}1 \mathrm{cem} \\
1 \%\end{array}$ & $\begin{array}{c}\text { komplett } \\
, "\end{array}$ \\
\hline
\end{tabular}

Wir sehen also aus diesen Versuchen, dass abgesehen von den oben erwähnten Substanzen vor allem den Organen dieselbe Eigenschaft zukommt, wie der Linse, dass sie also keine spezifische Eigenschaft der Linse ist. Wollten wir nun wirklich mit Römer glauben, dass diese komplementophilen Gruppen in der Linse zur Pathogenese der Katarakt in Beziehung stehen, dass mit ihrer Hilfe die Verankerung des Cytotoxins an die Linsenfaser erfolgt, so müssten wir dem Resultate unserer Versuche entsprechend auch annehmen, dass durch die gefundenen Gruppen eine Bindung der im Blute kreisenden Zellgifte an fast alle andern Organe stattfinden müsste. Wir 
wissen aber aus zahlreichen Tierversuchen, welch ausgedehnte pathologische Veränderungen und Zerstörungen - ob nun deren Entstehung hämolytische Vorgänge, wie jetzt fast allgemein angenommen wird, oder wirkliche cytotoxische zugrunde liegen - durch die Einwirkung von cytotoxischen Stoffen in fast allen Organen gesetzt werden. Demnach müssten auch beim Menschen, das Vorhandensein solcher Zellgifte vorausgesetzt, schwere Organveränderungen neben oder vor dem Altersstar zu beobachten sein.

Nun könnte man aber die Behauptung aufstellen, dass auch die Komplement absorbierende Fähigkeit von Organextrakten auf die von diesen losgelösten Receptoren zurückzuführen ist. Denn den Ehrlichschen Anschauungen entsprechend kann nur die komplementophile Gruppe des Amboceptors das Komplement verankern. Eine solche Anschauung wäre jedoch nur dann diskutierbar, wenn wir Zellemulsionen verwendet hätten, denn nur dann könnten tatsächlich die fixen Zellreceptoren die Komplementbindung veranlassen.

Niemals ist aber der Nachweis bisher gelungen, dass die im Serum vorhandenen Antikörper (Receptoren) in den Organzellen in wasserlöslichem Zustand vorhanden sind [Weil und Braun(14)]. Da wir aber bei unsern sämtlichen Versuchen nur den wässrigen Extrakt sowohl der Linse, als auch der Organzellen benützt haben, so können wir wohl mit Sicherheit behaupten, dass die in den Extrakten übergehenden Komplement absorbierenden Stoffe nicht identisch sind mit etwa vorhandenen Receptoren an Zellen, deren Existenz allerdings von vornherein nicht unbedingt zu leugnen ist; auch wenn ihr Nachweis bisher noch nicht geglückt ist.

Da wir wissen, dass die Linse sehr viel alkohollösliche Stoffe enthält, und dass insbesonders diesen, wie in der letzten Zeit bekannt wurde, die Fähigkeit der Komplementabsorption zukommt, so haben wir eine Reihe von entsprechenden Versuchen angestellt.

30 Schweinslinsen wurden in Alkohol $96 \%$ extrahiert, das gefällte Eiweiss abfiltriert, der Alkohol bei $60^{\circ}$ verjagt; dann der Rückstand in $20 \mathrm{cem} \mathrm{NaCl}$ emulgiert.

\begin{tabular}{|c|c|c|c|}
\hline Alkoholextrakt & $\begin{array}{c}\text { aktives Menschen- } \\
\text { serum }\end{array}$ & $\begin{array}{l}\text { Kaninchenblat- } \\
\text { körperchen }\end{array}$ & Hämolyse \\
\hline $\begin{array}{l}2,0 \mathrm{ccm} \\
1,0 " \\
0,5 " \\
0,1 " \\
0,05 "\end{array}$ & $\begin{array}{l}0,1 \mathrm{ccm} \\
0,1 " \\
0,1 " \\
0,1 " \\
0,1 "\end{array}$ & $\begin{array}{l}1 \mathrm{ccm} \\
1 " n \\
1 \\
1 \\
1\end{array}$ & $\begin{array}{l}\theta \\
\theta \\
\theta \\
\theta \\
\theta\end{array}$ \\
\hline
\end{tabular}




\begin{tabular}{|c|c|c|c|}
\hline Alkoholextrakt & $\begin{array}{l}\text { aktives Menschen- } \\
\text { serum }\end{array}$ & $\begin{array}{l}\text { Kaninehenblut- } \\
\text { körperchen }\end{array}$ & Hämolyse \\
\hline $\begin{array}{l}2,0 \mathrm{ccm} \\
1,0 \quad " \\
0,5 \quad " \\
0,1, " \\
0,05 "\end{array}$ & $\begin{array}{l}0,2 \mathrm{~cm} \\
0,2 " \\
0,2 " \\
0,2 " \\
0,2 "\end{array}$ & 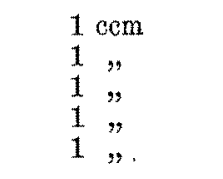 & $\begin{array}{c}\theta \\
\theta \\
\theta \\
\text { starke Hemmung } \\
,\end{array}$ \\
\hline $\begin{array}{l}\mathrm{NaCl} 2 \mathrm{ccm} \\
\quad, 2,\end{array}$ & $\begin{array}{l}0,1 \mathrm{~cm} \\
0,2 \%\end{array}$ & $\begin{array}{l}1 \mathrm{ccm} \\
1 \%\end{array}$ & $\begin{array}{c}\text { komplett } \\
",\end{array}$ \\
\hline
\end{tabular}

Dieser Versuch zeigt, dass die hemmende Wirkung der alkohollöslichen Substanzen in der Linse eine ungemein starke ist; einen Vergleich der Wirkung der Kochsalzemulsion der ganzen Linse und der extrahierten alkohollöslichen Substanzen allein zeigt der folgendeVersuch :

\begin{tabular}{|c|c|c|c|}
\hline & $\begin{array}{l}\text { aktives Menschen- } \\
\text { serum }\end{array}$ & $\begin{array}{l}\text { Nach } 1 \text { Stde, Bindung } \\
\text { Kaninchenblutk. } 5 \%\end{array}$ & Hämolyse \\
\hline $\begin{array}{c}\text { Linsenemulsion } \\
\mathrm{NaCl} \\
2,0 \mathrm{ccm} \\
1,0 \quad \\
0,5 \% \\
0,1 \% \\
0,05 "\end{array}$ & $\begin{array}{l}0,15 \mathrm{ccm} \\
0,15 \quad " \\
0,15 " \\
0,15 " \\
0,15 "\end{array}$ & $\begin{array}{ll}1 & \mathrm{ccm} \\
1 & " \\
1 & " \\
1 & " \\
1 & "\end{array}$ & $\begin{array}{c}\theta \\
\theta \\
\theta \\
\text { stark } \\
\text { komplett }\end{array}$ \\
\hline $\begin{array}{c}\text { Alkoholextrakt } \\
2,0 \mathrm{ccm} \\
1,0 " \\
0,5 " \\
0,1 " \\
0,05 "\end{array}$ & $\begin{array}{l}0,15 \mathrm{ccm} \\
0,15 " \\
0,15 " \\
0,15 " \\
0,15 "\end{array}$ & $\begin{array}{l}1 \mathrm{ccm} \\
1 " n \\
1 " \\
1 \% \\
1 " n\end{array}$ & $\begin{array}{c}\theta \\
\theta \\
\theta \\
\theta \\
\text { komplett }\end{array}$ \\
\hline $\begin{array}{l}\text { Kontrolle } \\
\mathrm{NaCl} 2 \mathrm{cem}\end{array}$ & $\begin{array}{c}0,15 \mathrm{ccm} \\
-\end{array}$ & $\begin{array}{l}1 \mathrm{cem} \\
1 "\end{array}$ & komplett \\
\hline
\end{tabular}

Aus diesen Versuchen geht mit aller Bestimmtheit hervor, dass die Komplement-bindende Wirkung der alkohollöslichen Substanzen in der Linse eine ebenso grosse, ja vielleicht noch grössere ist, als die der gesamten Linsensubstanz.

Gestützt auf diese Tatsachen und Versuche müssen wir zu dem Schluss gelangen, dass es sich hier nicht um eine spezifische Eigenschaft der Linse handelt, dass wir also nicht die Berechtigung haben, anzunehmen, dass die Fähigkeit der Komplementbindung nur der Linse zukommt. Dieselbe ist vielmehr eine Eigentümlichkeit der meisten Organzellen.

Dies wissen wir übrigens auch schon aus den zahlreichen Unter- 
suchungen über die Wassermannsche Reaktion, bei der ja die wichtigste Kontrolle darin besteht, zu prüfen, ob nicht die verwendete Konzentration der Organextrakte allein schon Komplement absorbiert.

Und weiters ist es durch unsere letztangeführten Versuche sehr wahrscheinlich gemacht, dass diese Fähigkeit zum allergrössten Teil den alkohollöslichen Stoffen in der Linse zukommt. Da aber nach allgemeiner Ansicht die Receptoren Eiweissnatur besitzen oder an Eiweiss gebunden sind, so müssen wir es demnach für erwiesen halten, dass es sich bei diesem Phänomen nicht um Receptorenwirkung handelnkann

Mit dem Nachweis, dass das Linsenprotoplasma einen Receptorenaufbau im Sinne Ehrlichs nicht besitzt, war eigentlich die Theorie von der Entstehung der senilen Katarakt durch cytotoxische Stoffe schon gefallen. Aber es war immerhin noch möglich, dass die Linse solche Stoffe aufzunehmen im stande wäre, wenn sie auch keine spezifisch wirkenden Aufnahmsapparate aufzuweisen hätte. Man brauchte nur anzunehmen, dass die Regulationsvorrichtungen im Bereiche der blutdurchspülten Organe die Zellgifte von denselben abhalten könnten, während die Linse - ganz ausserbalb der Blutcirkulation stehend - bei Funktionsunfähigkeit ihres lokalen Regulationsapparates, der Gefässwände und des Epithellagers der Ciliarfortsätze schutzlos den Cytotoxinen ausgesetzt sein könne. Oder es wäre möglich gewesen, dass andere Organe ebenfalls angegriffen würden, die Folge der Giftwirkung auf dieselben aber nur vorübergehend, bald wieder kompensiert oder überhaupt olne grosse Bedeutung wäre, während sie bei der Linse, einem so empfindlichen Organ, dessen Funktion als brechendes Medium mit dem Verlust seiner Klarheit erlischt, weit mehr ins Gewicht fallen könnte.

Es war also weiter unsere Aufgabe, die Funktion der sekretorischen Apparate des Auges bei starkranken Menschen zu untersuchen. - Das für das normale Auge von Wessely gefundene, von Römer weiter ausgebaute und formulierte Gesetz der Cytotoxinretention durch die sekretorischen Apparate des Auges haben wir bereits erwähnt; es wäre nur noch hinzuzufügen, dass nicht nur die normalerweise im Serum enthaltenen Lysine für bestimmte Blutarten vom Ciliarkörper vollständig zurückgehalten werden, sondern dass auch das Gesetz dann Geltung hat, wenn die cytolytischen Stoffe auf künstlichem Wege - durch Immunisierung - hundert- und tausendfach vermehrt werden. Auch dann weist das Kammerwasser keine oder kaum Spuren dieser Antikörper auf, während nach Römer gewisse Agglutinine in dasselbe wohl eintreten können. 
Es war von vornherein klar, dass aus Tierversuchen kein Schluss auf das Verhalten des Ciliarkörpers beim kataraktösen Menschen möglich sein werde. Denn wenn es auch Tiere gibt, die in höherem Alter an Star erkranken, so lag keine Berechtigung vor, diesen Star als einen dem menschlichen Altersstar vollkommen analogen anzusehen; und so hätte den umständlichen Versuchen, ganz abgesehen davon, dass das Material für dieselben sehr schwer zu beschaffen gewesen wäre, von Anfang an strikte Beweiskraft gefehlt.

Es mussten also diese Versuche am Menschen durchgeführt werden und dabei standen uns verschiedene Wege zur Verfügung. Wir konnten das Kammerwasser auf das Vorhandensein der im normalen menschlichen Serum vorhandenen Amboceptoren prüfen, oder konnten auf dem Wege der aktiven oder passiven Immunisierung Amboceptoren in grosser Menge künstlich erzeugen. Dass alle diese Mittel zur Prüfung des Gesetzes der Ciliarkörperretention zulässig sind, erhellt aus den darauf bezüglichen Versuchen von Römer und Wessely.

Nun war weiter die Wahl zwischen Hämolysinen und andern Cytotoxinen, oder Bakteriolysinen bzw. Agglutininen zu treffen.

Die beiden ersteren Stoffe mussten von vornherein für Versuche am Menschen ausgeschlossen werden, weil ihre Anwendung im höchsten Grade bedenklich ist; nicht nur deswegen, weil das zu injizierende Material schwierig keimfrei zu machen ist, sondern weil auch erfahrungsgemäss die Injektion häufig unangenehme und langdauernde aseptische Eiterungen hervorrufen kann, besonders aber der Gefahr der Anaphylaxie wegen, die nach den Untersuchungen von Uhlenhuth und Andern für diese Stoffe sehr bedentend ist.

Es bleiben also nur die letztgenannten Stoffe übrig und zwar entschieden wir uns für die aktive Immunisierung, weil gerade auf diesem Wege sehr rasch die Bildung einer grossen Menge von Antikörpern möglich ist.

Ein 68jäluiger Patient, bei dem die interne Untersuchung bis auf leiehte Gefässsklerose vollkommen normale Verhältnisse festgestellt hatte, und der rechts einen maturen, links einen stark immaturen subkapsulären Rindenstar zeigte, erhielt in $Z$ wischenräumen von fünf Tagen vier Injektionen einer abgetöteten Vibrionenkultur in physiologiseher Kochsalzlösung und zwar enthielt die erste Aufschwemmung ${ }^{1}{ }_{10}$, die späteren 1, 2, 3 Ö́sen der Kultur. Neun Tage nach der letzten Injektion, nachdem also erfahrungsgemäss der Höhepunkt der Antikörperbildung erreicht war, wurde ein Quantum Blut entnommen.

Das Kammerwasser wurde bei der beiderseits gleichzeitig vorgenommenen Extraktion der Katarakt in der Weise gewonnen, dass zuerst der Binde- 
hautsack sorgfaltig trocken ausgetupft und dann nach sehr langsam und vorsichtig ausgefülartem Lappenschnitt die unter dem abgezogenen unteren Lid angesammelte Flissigkeit rasch mit der Pipette aufgesogen wurde. Die Menge betrug des unvermeidlichen Verlustes wegen nur ungefähr $0,15 \mathrm{cem}$.

Der Versuch ergab:

Vor der Immunisierung:

\begin{tabular}{c|c|c}
\hline \hline Blutserum & Vibrionenemulsion & Agglutination \\
\hline \hline $1: 25 \mathrm{NaCl}$ & $1 \mathrm{ccm}$ & $\theta$ \\
$1: 50 "$ & $1 \mathrm{n}$ & $\theta$
\end{tabular}

nach zweistündiger Beobachtung bei $37^{\circ}$ und $50^{\circ}$ :

Inmunserum (Vorversuch am 9. Tag).

\begin{tabular}{c|c|c}
\hline Blutserum & Vibrionen & Agglutination \\
\hline $1: 25 \mathrm{NaCl}$ & $1 \mathrm{ccm}$ & (Hemmende Zone) \\
$1: 50$ " & $1 \%$ & + \\
$1: 100 \%$ & $1 \%$ & ++ \\
$1: 200 "$ & $1 \%$ & +++ \\
(nicht austitriert) & $1 \mathrm{ccm}$ & $+\frac{1}{+}$ \\
$1 \mathrm{ccm} \mathrm{NaCl}$ & $1 \mathrm{c}$ &
\end{tabular}

Vibrionenemulsion $=1$ Vibrionenagarkultur auf $20 \mathrm{cem} \mathrm{NaCl}$.

Hauptversuch:

\begin{tabular}{c|c|c}
\hline Kammerwasser & Vibrionen & Agglutination 50 \\
\hline $1: 50 \mathrm{NaCl}$ & $1 \mathrm{ccm}$ & $\theta$ \\
$1: 100 "$ & $1 "$ & $\theta$ \\
$1: 200$, & $1 "$ & $\theta$ \\
\hline Blutserum & & \\
$1: 50 \mathrm{NaCl}$ & $1 \mathrm{ccm}$ & +++ \\
$1: 100 \%$ & $1 \%$ & +++ \\
$1: 200 "$ & $1 \% "$ & +++ \\
$1: 400 \%$ & $1 \%$ & ++ \\
(nicht austitriert) & &
\end{tabular}

\section{Versuch II.}

60jährige Fran, bei der die interne Untersuchung bis auf Bronchitis normale Verhältnisse ergeben hatte. Rechts immaturer, subkapsulärer Rindenstar, links zarte Speichen in der vorderen und hinteren Rinde. Die Patientin erhielt im ganzen drei Injektionen, genau so dosiert, wie im oben geschilderten Versuch. Während der erste Patient die Injektionen ohne weiters vertragen hatte, trat hier nach der ersten nnter ganz leichter Temperatursteigerung ein geringes toxisches Erythem auf, welches nach drei Tagen vollkommeu abgeklungen war. Bei den übrigen Einspritzungen trat keine Reaktion mehr auf, nicht einmal in Form einer Temperaturerhöhung.

צ. Graefe's Archiv für Ophthalmologie. LXXI. 3. 
Sowie im ersten Versuche wurde acht Tage nach der letzten Injektion das Blut untersucht und da dasselbe grossen Reichtum an Antikörpern aufwies, einige Stunden darauf das Kammerwasser entnommen. Letzteres geschah nicht, wie beim ersten Fall, bei der Extraktion, sondern wurde durch beiderseitige Punktion mit einer Wessely-Nadel in einer Menge von ungefähr 0,25 gewonnen. Die geplante Extraktion musste einer Exacerbation der Bronchitis wegen aufgeschoben werden. Der kleine Eingriff wurde vollkommen gut vertragen.

Vor der Immunisierung:

\begin{tabular}{l|c|c}
\hline \hline Blutserum & Vibrionen & Agglutination \\
\hline $1: 10 \mathrm{NaCl}$ & $1 \mathrm{ccm}$ & $\theta$ \\
$1: 20 \%$ & $1 \%$ & $\theta$ \\
$1: 50 \%$ & $1 \%$ & $\theta$
\end{tabular}

Immunserum:



Kammerwasser:

\begin{tabular}{c|c|c}
\hline Kammerwasser & Vibrionen & Agglutination \\
\hline $1: 10 \mathrm{NaCl}$ & $1 \mathrm{ccm}$ & $\theta$ \\
$1: 20 "$ & $1 \mathrm{\theta}$ & $\theta$ \\
$1: 50$, & $1 \%$ & $\theta$ \\
$1: 100 "$ & $1 "$, & $\theta$
\end{tabular}

Wir sehen also aus diesen beiden Versuchen, dass niemals, auch wenn der Agglutinationstiter des Serums noch so gross war, die Agglutinine für unsere Vibrionen in das Kammerwasser übergingen. Nach dem Ausfall dieser Versuche konnten wir die Untersuchung der bakteriolytischen Wirkung ruhig unterlassen. Denn es hat ja Römer selbst festgestellt, dass nicht einmal in Fällen, wo Agglutinine übergingen, Hämolysine zu finden waren, dass also normalerweise jene viel leichter durch den Ciliarkörper mit seinen Epithelien hindurchgehen, als die Antikörper dritter Ordnung.

Es steht daher zweifellos fest, dass der Ciliarkörper des Starkranken, wenn er schon die Agglutinine zurück- 
zuhalten im stande ist, um so mehr für Cytotoxine undurchgängig sein wird.

Trotzdem hätten wir das Kammerwasser auch auf seine bakteriolytische Wirkung untersucht, doch war uns dies nicht möglich, weil die Menge desselben nicht hinreichte. Wir haben daher den Versuch nochmals wiederholt, um auch das Verhalten gegenüber Receptoren dritter Ordnung ganz einwandsfrei feststellen zu können.

\section{Versuch III.}

Der 70jährige Patient (intern ohne Besonderheiten, rechts maturer, links immaturer typischer subkapsulärer Rindenstar) erhielt mit einern Zwischenraum von 5 Tagen zwei Injektionen und zwar das erstemal 1,5, das zweitemal $3 \mathrm{ccm}$ einer ganzen in $20 \mathrm{ecm} \mathrm{Na} C l$ aufgeschwemmten abgetöteten Vibrionenkultur. Am 11. Tag wurde das Kammerwasser durch beiderseitige Punktion mit der Nadel (Menge wegen starken Verlustes nur etwas mehr als $0,1 \mathrm{ccm}$ ) und gleichzeitig etwas Blut entnommen. Nachdem wir uns in einem Vorversuch orientiert hatten, welches die gïnstigen Mengenverhältnisse zwischen den Vibrionenimmunkörpern und dem Komplement waren, wurde der Versuch in folgender Weise ausgeführt:

\begin{tabular}{|c|c|c|c|}
\hline Immunserum & $\begin{array}{c}\text { Komplement } \\
\text { (Meerschweinch.) }\end{array}$ & Nach einer Stunde & $\begin{array}{l}\text { Agglu- } \\
\text { tination }\end{array}$ \\
\hline $\begin{array}{c}0,002 \\
0,002 \\
0,01 \\
0,01 \\
\text { Kammer- } \\
\text { wasser } \\
0,07 \\
0,05 \\
-\end{array}$ & $\begin{array}{l}0,05 \\
0,02 \\
0,05 \\
0,02\end{array}$ & $\begin{array}{c}\text { Nur Granula } \\
4 / 5 \text { Granula, } 1 / 5 \text { Vibrionen } \\
\text { Nur Granula } \\
1 / 5 \text { Granula, 1/5 Vibrionen } \\
\\
4 / 5 \text { Vibrionen, } 1 / 5 \text { Granula in Haufen } \\
\text { nur Vibrionen } \\
4 / 5 \text { Vibrionen, } 1 / 5 \text { Granula in Haufen } \\
\text { nur Vibrionen }\end{array}$ & $\begin{array}{l}+\frac{1}{+} \\
++ \\
+t+ \\
+t+\end{array}$ \\
\hline
\end{tabular}

Diese von uns gefundenen Tatsachen beweisen also, dass das durch Römer aufgestellte Gesetz der Cytotoxinretention des Ciliarkörpers auch für den starkranken Menschen Geltung hat, dass also, selbst wenn solche cytotoxische Stoffe, wie sie Römer annimmt, entstehen würden, die linse vor ihrer Giftwirkung geschützt bliebe.

Mit diesen Tatsachen ist demnach die ätiologische Bedeutung der Oytotoxine fur die Pathogenese des Altersstars im negativen Sinne entschieden.

Nun ist aber die Frage aufzuwerfen, ob es überhaupt möglich ist, dass derartige Stoffe antikörperartiger Natur im Organismus entstehen können. Denn nur dann wird der Organismus mit der Bildung solcher Reaktionsprodukte antworten, wenn die Stofle, die dieselben 
hervorrufen sollen, als körperfremd empfunden werden. In der Tat ist es experimentell sicher gestellt, dass man mit körperfremden Eiweissstoffen und zwar desto leichter, je mehr sie es sind, Antikörper zu erzeugen vermag. Anfangs war deshalb der Gedanke naheliegend, das körpereigene und arteigene Stoffe hierzu nicht befähigt sind. Jedoch hat A scoli bewiesen, dass für die letzteren wenigstens, die arteigenen, Antikörperbildung zweifellos möglich ist. Betreffs der ersteren herrschte lange Zeit Unklarheit. Es wurden zwar Beobachtungen beschrieben, wo insbesondere nach der Resorption von Blutzellen im eigenen Organismus Autolysine und Autoagglutinine entstehen. Diese Beobachtungen erhielten aber eine starke Einschränkung besonders durch die Mitteilungen Landsteiners und seiner Mitarbeiter, welche das Vorhandensein derartiger Stoffe in wahllos untersuchten Fällen sowohl bei normalen, als bei erkrankten Individuen nachweisen konnten. Demnach ist es also sehr fraglich, ob diese gegen die eigenen Blutkörperchen gerichteten Stoffe wirklich einem Autoimmunisierungsprozess ihre Entstehung verdanken.

Eine ganz andere Frage aber ist es - und diese steht heute im Mittelpunkt des Interesses und ist auch für unser Thema ganz besonders wichtig - , ob andere Gewebselemente, welche im Organismus zur Resorption gelangen, die Bildung von Antikörpern bedingen können.

Hierfïr kommen zunächst Zellstoffe aus dem Organverband in Betracht, welche im Körper durch Abbau, Schädigung zum Zerfall und zur Resorption gelangen. Dass unter dem Einfluss von Degenerationsvorgängen im Organismus solche oder äbnliche Stoffe entstehen können, ist durch die Wassermannsche Reaktion bei der Lues wahrscheinlich gemacht. Mit Hilfe dieser Reaktion, der Methode der Komplementbindung, müsste es demnach gelingen, die bei der Katarakt in Betracht kommenden Antikörper nachzuweisen. Römer konnte nun mit Hilfe dieser Reaktion feststellen, dass bei normalen, das ist nicht starleidenden Individuen Antistoffe gegen die Linse vorhanden sind.

Freilich fasst Römer diese von ihm mittels der Komplementbindung gefundenen Stoffe als cytotoxisch auf. Obschon wir nun heute fast mit absoluter Sicherheit wissen, dass die mittels dieser Reaktion nachgewiesenen Stoffe nicht Amboceptorennatur besitzen, sondern als Präcipitine anfzufassen sind, so wäre es doch immerhin möglich, dass neben solchen auch cytotoxische normalerweise gegen die Linse gerichtete Stoffe vorhanden sind.

Offenbar müssen aber dann die mittels der Komplèmentbindung 
nachweisbaren Stoffe bei dem an seniler Katarakt Leidenden vermehrt sein.

Schon Römer musste diese Frage im negativen Sinne beantworten; seine Versuche ergaben, dass diesbezügliche qualitative Unterschiede zwischen dem Serum junger, alter und altersstarkranker Individuen nicht vorhanden sind.

Bei dieser Gelegenheit wäre noch zu bemerken, dass die gleichfalls von Römer gefundene Tatsache, dass die hier in Betracht kommenden Stoffe im Serum des Fötus fehlen, ein Befund, dem er grosse Bedeutung beizumessen scheint, nicht zu. Schlüssen irgendwelcher Art berechtigt. Denn es ist durch Halban und Landsteiner, sowie durch Schenk(28) nachgewiesen, dass im fötalen Serum alle derartigen Stoffe, Hämolysine, Agglutinine, Präcipitine usw. sehr stark vermindert sind, und Römer selbst führt als Beispiel hierfür in seiner ersten Arbeit an, dass das mütterliche Serum ein Hämolysin gegen Taubenblut enthält, das fötale dagegen nicht (Polano).

So darf also das Fehlen auch der uns hier interessierenden Stoffe gar nicht wundernehmen und stimmt nur vollkommen zu den sonst bekannten Tatsachen.

Auch wir haben Sera mittels der Komplementbindungsreaktion untersucht und sind dabei zu nicht uninteressanten Resultaten gekommen.

$2 \mathrm{ccm}$ und $1 \mathrm{ccm}$ Linsenextrakt (2 Rinderlinsen in $45 \mathrm{ccm} \mathrm{NaCl}$ ) + Mecrschweinchenkomplement $0,1+0,2$ Serum (inaktiviert) kommen auf eine Stunde in den Brutschrank.

Darauf Zusatz des hämolytischen Systems, bestehend aus Hammelblutamboceptor [rom Kaninchen 0,003 (dreifachlösende Dosis) + 1 com Hammelblutkörperchen] in $5 \%$ Lösung:

\begin{tabular}{|c|c|c|c|c|}
\hline Linsenextrakt & Serum & Komplement $1: 10$ & & Blutkörperchen $5 \%{ }_{0}^{0}$ sensibilisiert \\
\hline $\begin{array}{l}2 \\
1 \\
2 \\
1 \\
-\end{array}$ & $\begin{array}{l}0,2 \\
0,2 \\
- \\
- \\
0,2\end{array}$ & $\begin{array}{l}1 \\
1 \\
1 \\
1 \\
1\end{array}$ & 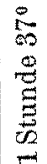 & $\begin{array}{l}1 \\
1 \\
1 \\
1 \\
1\end{array}$ \\
\hline
\end{tabular}

Nach diesem Schema ergaben von 3 normalen Seris eines Komplementbindung in der stärksten Konzentration, von 4 von Kataraktleidenden •, ebenfalls nur in der stärksten Konzentration, von 4 luetischen Seris (mit vorher geprüfter + Wassermannreaktion) 3 in der stärksten, einer auch noch in der schwachen Konzentration. 
I. Normales Serum (jugendliches Individuum):

\begin{tabular}{c|c|c}
\hline Linsenextrakt & Serum & Resultat \\
\hline 1. $2 \mathrm{ccm}$ & 0,2 & $\theta$ \\
$2.1, "$ & 0,2 & komplett \\
$3.45 \mathrm{ccm}$ & 0,2 & $"$, \\
Kontrollen & - & $"$,
\end{tabular}

II. Normales jugendliches Serum (nach derselben Versuchsanordnung):
1. Komplett.
2. Komplett.
3. Komplett.

III. Normales Serum eines älteren Mannes:
1. Komplett.
2. Komplett.
3. Komplett.

IV. V. VI. VII. Sera von Individuen mit subkapsulärem Rindenstar: IV. V.

VI.

VII.
1. stark
1. stark
2. komplett
2. komplett
3. "
3. "
1. komplett
1. komplett
2. $"$
3. $"$
2. "
3.

VIII. IX. X. XI. Sera von Luetikern:

VIII.

IX.

$\mathrm{X}$.

XI.

1. komplett

1. $\theta$

1. $\theta$

1. $\theta$

$2 . \quad$ "

2. komplett

3.

3. "

2. $\theta$

3. komplett

2. komplett

3. "

Diese Versuche beweisen vor allem, dass irgendwelche erhebliche Unterschiede der Komplement bindenden Stoffe des kataraktösen gegeniber dem normalen Serum nicht bestehen. Sie zeigen ferner, dass die von $R o ̈ m e r$ gesuchten Stoffe bei Luetikern häufiger vorzukommen scheinen. Dieselben besitzen jedoch sicherlich keine für die Linse spezifische Bedeutung; da wir ja wissen, dass die Komplement bindenden Stoffe luetischer Sera mit dem Extrakt aller möglichen Gewebe und sonstiger chemischer Substanzen in Reaktion treten, so darf es nicht wundernehmen, dass sie dies auch mit dem Linsenextrakte tun.

Gerade durch diese Tatsache ist es aber sehr wahrscheinlich gemacht, dass die gefundenen Stoffe in keiner Beziehung zum Altersstar stehen. Denn nirgends in der Literatur ist von irgendeinem Zusammenhang zwischen der Lues und dem Altersstar die Rede; alle klinischen Erfahrungen beweisen, dass die Lues, der doch sonst soviel in die Schuhe geschoben wird, eine Bedeutung für die Ätiologie der senilen Katarakt nicht zukommt. Und doch müsste man dies nach dem Ausfall der Komplementbindung und in Konsequenz der Ansichten Römers erwarten. So ergaben also auch die Ver- 
suche mit dieser Methode, auf die Römer so grosse Hoffnungen gesetzt hatte, dass kein Anlass vorliegt, ein Entstehen des Altersstars durch Cytotoxine anzunehmen.

Nachdem wir gezeigt haben, dass Stoffe von der Art der Autocytotoxine für die Entstehung des Altersstars nicht in Betracht kommen können, erübrigt uns noch, auf die Frage einzugehen, ob Toxine anderer Natur für dieselbe verantwortlich gemacht werden können. Denn es hat ja Römer, wie bereits erwähnt, die erstere Annahme nur aus heuristischen Gründen gemacht, und seine in den später erschienenen Arbeiten niedergelegten Untersuchungen beweisen, dass er durchaus nicht einseitig auf seinem Standpunkt beharrt.

Veranlasst war dieser Teil seiner Untersuchungen in erster Reihe durch die Mitteilungen A. Lebers (15) über den Stoffwechsel der Krystallinse.

Leber fand eine besondere Affinität der sogenannten lipoidlöslichen Stoffe zur Linse, die bedingt war durch den Gehalt der Linse an Cholesteárin und Lecithin.

Da nun solche lipoidlösliche Stoffe im Organismus unter pathologischen Bedingungen manchmal vorkommen, so das Aceton, die Acetessigsäure und $\beta$-Oxy-Buttersäure, da ferner die kataraktöse Linse Lipoide in grösserer Menge enthält, so glaubt Leber aus der gefundenen Tatsache der innigen Beziehungen dieser lipoidlöslichen Substanzen zu den Lipoiden wichtige Schlüsse auf die Ursachen des Altersstars ziehen zu können.

Es hat nun Römer vor allem Gross (16) veranlasst, der Frage näher zu treten, ob der Gehalt der kataraktösen Linse an Lipoiden wirklich grösser sei, als der der gleichaltrigen klaren.

Gross konnte nur durch Extraktion gewonnene Kerne startrüber Linsen untersuchen, diesen aber aus Mangel an Material Untersuchungen an gleichaltrigen klaren zum Vergleiche nicht gegenüber stellen.

Es ergab sich jedoch aus dem Vergleiche alter und junger Kuhlinsen, dass der Cholestearingehalt bei den ersteren keine Vermehrung erfährt.

Freilich kommt, wie ich glaube, diesen Ergebnissen volle Beweiskraft nicht $z u$; denn da ja Leber in der Vermehrung der Lipoide die Ursache der Katarakt sieht, so konnten vergleichende Bestimmungen dieser Art nur dann eine Entscheidung bringen, wenn sie an Tieren vorgenommen wurden, welche an einem dem des Menschen 
analogen Altersstar erkranken; denn nur dann war ja nach Leber eine Vermehrung der Lipoide zu erwarten. Zurzeit stehen aber meines Wissens Untersuchungen über die Starbildung bei Kühen noch aus.

Weiters konnte Gross feststellen, dass der Acetongehalt des Harns älterer Personen mit den verschiedensten Augenerkrankungen gegenüber dem bei Katarakt keinen Unterschied aufweist, daher dem Vorkommen dieses Stoffes auch keine ursächliche Bedeutung beigemessen werden kann. Wichtiger sind die Untersuchungen Römers. selbst uiber diese Frage, die zwar die Angabe Lebers, dass das Aceton in die Linse sehr leicht eindringen könne, vollkommen bestätigten, zugleich aber eine Giftwirkung dieser Substanz auf die Linse aus dem Fehlen der Kriterien einer solchen, der Gewichtsänderung und Eiweissabgabe von seiten der Linse ausschliessen konnten.

So ist es also, wie Gross hervorhebt, sehr wahrscheinlich, dass, wenn wirklich in startrüben Linsen der Gehalt an Lipoiden vermehrt ist, diese Vermehrung nicht Ursache, sondern Folge des kataraktösen Zerfalles ist, denn „überall, wo epitheliales Gewebe eine Nekrobiose eingeht, bildet sich Cholestearin" (Gross).

Weiters hat erst jüngst Kuw a bara (17) auf Veranlassung Röm ers. ausgedehnte und mühevolle Untersuchungen über die Einwirkung organischer und anorganischer Stoffe auf die Linse angestellt mit dem Ergebnis, dass schon im normalen menschlichen Organismus. vorkommende Stoffwechselprodukte, wie beispielsweise das Ammoniumkarbonat und -karbamat, die Fähigkeit haben, auch in stark verdünnten Lösungen die Linse zu schädigen. Aber auch den bei Stoffwechselstörungen auftretenden Substanzen, der $\beta$-Oxy-Buttersäure, Acetessigsäure, deren Ammoniumsalzen usw. kommen analoge Wirkungen zu.

Auch diesen gewiss sehr interessanten Resultaten kann vorläufig keine Bedeutung für die Erschliessung der Ursache des Altersstars beigemessen werden; notwendig sind dazu erst noch Versuche, die die Vermehrung, beziehungsweise das regelmässige Vorkommen solcher Stoffe beim starbehafteten Menschen nachweiser. Dies trifft aber, soweit aus klinischer Erfahrung bekannt ist, nicht zu. Die erwähnten Stoffe finden wir bei sehr vielen Individuen, meist als Ausdruck einer schweren Ernährungsstörung. Häufigeres Auftreten von Katarakt (d. h. reiner Alters-, nicht etwa der diabetischen) ist dabei nicht beobachtet.

An dieser Stelle muss ich auch auf eine andere Theorie über die Entstehung des Altersstars eingehen, die in sehr vielen Punkten mit der 
Römers übereinstimmt. Es ist die Posseks, eines Autors, der sich auch mit Untersuchungen über die Pathogenese der Tetaniekatarakt beschäftigt hat und dessen interessante, jüngst publizierte Versuche wir später noch zu besprechen Gelegenheit haben werden. Possek(18) fasst den Altersstar auf als eine Autotoxikose, „bei welcher Störungen gewisser Blutdrüsen die normale regulatorische Entgiftung autotoxischer Stoffe verhindern und so die Anwesenheit derartiger Linsengifte in der Blutbahn bedingen".

Dadurch, dass Possek diese Stoffe nicht näher charakterisiert, nicht wie Römer sie als Cytotoxine auffasst, fällt für seine Hypothese die Notwendigkeit weg, ein Versagen des normalerweise Körper vom Baue der Cytotoxine zurückhaltenden sekretrorischen Apparates des Auges anzunehmen; trotzdem teilt auch er "Veränderungen der normalen Cirkulation in den Ciliarkörpergefässen, vielleicht auch degenerativen Prozessen in den Epithelien" eine Rolle zu. Vor allem aber sind die von ihm angenommenen Störungen im Bereich der grossen Blutdrüsen lokalisiert; hier ist demnach der Ausgangspunkt der Erkrankung zu suchen.

Beide Theorien, die Römers und die Posseks, besagen fast das gleiche.

Der eine nimmt Cytotoxine an - nicht spezifische, denn sie entstehen aus allen möglichen Zellen des Körpers -, die spezifisch auf die Linse und nur auf die Linse einwirken sollen; und die Linse, gerade nur die Linse unter allen Organen des menschlichen Körpers allein soll spezifische Aufnahmsapparate für diese Gifte besitzen.

Possek wieder ist der Ansicht, dass die für den Organismus so überaus wichtigen Blutdrüsen - oder eine von ihnen - ihre entgiftende Tätigkeit einstellen und dass keine andere Störung im Organismus, sondern eben wieder nur eine Katarakt auftritt! Heisst das nicht die Linse zu einem der wichtigsten Organe des menschlichen Körpers stempeln?

Die Theorie Posseks gibt eine ausgezeichnete Erklärung für die Entstehung z. B. der Tetanie- oder der diabetischen Katarakt; gerade bei diesen Starformen aber sieht man, welche Folgen eine solche von Possek auch für den Altersstar angenommene Blutdrüsenerkrankung mit sich bringt. Denn hier ist der Star kompliziert durch Störungen des Gesamtorganismus, denen gegenüber die Erkrankung der Linse stark in den Hintergrund tritt. Bei den Trägern der echten Alterskatarakt aber fehlen alle solche Erscheinungen; es handelt sich gewöhnlich um ganz kerngesunde In- 
dividuen, die keine andern Störungen, ja nicht einmal eine grössere Gefässsklerose, weder im Bereiche des betroffenen Auges, noch im Körper zeigen, als sie eben ihrem Alter physiologischerweise zukommt. Diese wichtige Erfahrungstatsache ist es, die bis jetzt all die zahlreichen Theorien, welche die Ursache des Altersstars im Gesamtorganismus gesucht haben, zunichte gemacht hat; es gilt dies sowohl von der Meinung Deutschmanns, Grillis, Ducasse, die chronische nephritische Prozesse zur senilen Katarakt in Beziehung bringen, als auch von der v. Michels, der das Atherom der Carotis verantwortlich macht, und von der mit der Ansicht Posseks identischen Annahme von Pineles.

Und dasselbe Schicksal werden meiner Überzeugung nach auch die beiden neuesten Theorien haben. - Wenn wir berücksichtigen, dass es zum Wesen der reinen senilen Katarakt gehört, dass bei ihren Trägern keine Erkrankung nachweisbar ist, die in Beziehung zur Starbildung stehen könnte, wenn wir ferner bedenken, dass auch das betroffene Auge bis auf die so regelmässig in jedem senilen Auge beobachteten Veränderungen vollkommen gesund ist, dass ferner die Linse ein epitheliales Gebilde ist und ihr als solchem analog andern Organen, die ihre Entstehung dem Ektoderm verdanken, nur geringe Bedeutung im Körperhaushalte zukommt, so muss die Auffassung sich geradezu aufdrängen, dass die senile Katarakt eine reine Alterserscheinung ist, der einfache senile Zellzerfall in der Linse.

Es ist nicht verständlich, warum Römer einen solchen gerade in der Linse leugnen will, wenn er dem senilen Zerfall in allen übrigen Organen des Körpers eine so grosse Rolle zuschreibt.

Natürlich muss sich ein solcher Prozess innerhalb der Linse etwas anders abspielen, als in andern blutdurchspülten und nicht allenthalben von einer Kapsel umgebenen Organen. Die zerfallenen Zellen bleiben in der Liuse liegen und gehen degenerative Veränderungen ein, die zum Verluste der Durchsichtigkeit führen müssen.

Dem Verbalten der Linse ganz analog sehen wir ja auch im Bereich aller andern ektodermalen Gebilde solche senile Veränderungen auftreten; auch diese zeigen das Sprunghafte, Unregelmässige, dieselben grossen individuellen und zeitlichen Differenzen, wie sie zum Wesen des Altersstars gehören.

Keine der bestehenden Theorien ist im stande, besser das klinisch so übercus sichergestellte hereditäre Auftreten der senilen Katarakt begreiflich zu machen, als die Auffassung derselben als reine Alterserscheinung. Denn man kann sich die Heredität - nicht erklären -, 
aber sie doch verständlicher finden, wenn man Analogien an andern Gebilden des Ektoderms ganz alltäglich beobachtet, als wenn man sich zum Beispiel eine erbliche Disposition zu regelmässigem Auftreten von Toxinen vorstellen müsste.

Wenn Römer der Meinung ist, dass die Alterskatarakt nur einen ganz geringen Bruchteil aller alten Menschen befalle, so steht er in direktem Widerspruch zu Hess und Greeff $(19)$, die ausdrücklich hervorheben, dass man bei sorgfältigster Untersuchung der Linsen von Leuten jenseits des 60. Jahres das Fehlen jeglicher Trübung sogar ziemlich selten finde.

Damit sehr gut im Einklang stehen statistische Untersuchungen an einem grossen Material, wie sie z. B. E. Jackson (20) angestellt hat. Nach diesen wiesen von 1545 untersuchten Leuten über 50 Jahre 449 Linsentrübungen auf und zwar im Alter von 50-55 Jahren 15\%, 55-60 Jahren 16,1\%, 60-65 Jahren 30,2\%, 65-75 Jahren $77 \%$; dabei kann man aus dem Referat noch nicht ersehen, ob wirklich unter voller Anwendung der uns zu Gebote stehenden Technik, also bei maximaler Mydriase und Anwendung des Lupenspiegels untersucht wurde.

Wenn man dies alles sich vor Augen hält und ferner noch berïcksichtigt, dass Leute in dem hohen Alter, wie es hier in Betracht kommt, gewiss seltener, oft auch gar nicht mehr den Augenarzt aufsuchen, weiter, dass dann sehr häufig selbst Atropininstillation eine für exakteste Untersuchung nur ungenügende Mydriase erzeugt, so kann der Satz nicht gewagt klingen, dass jeder Mensch einen Altersstar bekommen muss, wenn er ihn erlebt.

Dass nicht nur klinische Überlegungen, sondern auch das Wesen des Trübungsprozesses in der Linse selbst auf diese Ansicht hinweisen, ersehen wir aus den Arbeiten Greeffs (loc. cit.), der rein auf Grund seiner pathologisch-anatomischen Untersuchungen zu derselben Uberzeugung gelangt ist.

Wir müssen also zu dem Schlusse gelangen, dass nicht nur der Cytotoxin-Theorie Römers, sondern auch allen andern Ansichten, die die letzte Ursache des Altersstars im Gesamtorganismus suchen, jede Berechtigung abzusprechen ist und dass die Auffassung des reinen Altersstars als einfache Alterserscheinung bei weitem die meiste Wahrscheinlichkeit für sich hat.

Wir kommen zum zweiten Teil unserer Untersuchungen, der der Beurteilung der Lentokalintherapie Romers gewidmet ist. 
Von der Ansicht, dass die Katarakt durch im Blute des senilen Individuums kreisende, eine spezifische Affinität zur Linsensubstanz aufweisende Giftstoffe bedingt sei, war kein weiter Weg zu dem Gedanken, diese Gifte im Blute selbst durch eingeführte Linsensubstanz abzufangen, und dieselben so za paralysieren; und dies um so leichter, als die theoretische Möglichkeit einer solchen schon im Kreislauf ror sich gehenden Verankerung experimentell erwiesen schien.

Römer hatte gefunden, dass durch Immunisierung mit Linseneiweiss das Blutserum erhebliche Veränderungen erfährt. So unterschied sich das Serum eines mit Rinderlinsen immunisierten Hammels einmal dadurch vom normalen, dass die sonst vorhandenen Agglutinine für Kaninchenblut verschwunden waren; ferner war das der Linse eigentümliche Antitetanolysin nicht assimiliert worden, sondern durch längere Zeit noch im Serum des Immuntieres nachweisbar. Endlich war im Antilinsenserum die komplementophile Gruppe der Linse verschwunden.

Konnte man nun noch annehmen, dass diejenigen Gruppen in der Linse, die der Verankerung des Tetanolysins dienen, auch andere toxische Produkte an sich zu binden vermöchten, so schien es nicht schwer, durch Einführung dieses Antikörpers (der Linse) in den Kreislauf schon im Blute die schädlichen Stoffe $\mathrm{zu}$ verankern und ron der Linse des Individuums fernzuhalten, in derselben $W$ eise, wie das Diphtherietoxin durch Einführung des spezifischen Antitoxines von den Geweben ferngehalten wird (Römer).

Dass diese Annahme tatsächlich nicht von der Hand gewiesen werden kann, hat erst unlängst Possek(21) durch sehr interessante Versuche festgestellt.

Bekanntlich treten bei der Vergiftung mit Naphthalin Linsentriibungen und Netzhautveränderungen auf, die jedoch nicht durch das Naphthalin als solches, sondern durch die von demselben veranlasste Bildung toxischer Stoffe im Blute hervorgerufen sind (Hess loc. cit.).

Possek gibt einem Kaninchen intraperitoneal eine Linsenemulsion, und 12-24 Stunden später, also zu einer Zeit, wo noch Linsensubstanz im Blute enthalten sein dürfte, eine bestimmte Dosis Naphthalin durch die Magensonde. Kurze Zeit darauf zeigten seine Tiere wohl ausgedehnte Netzhautveränderungen, jedoch keine mit dem Spiegel nachweisbare Linsentrübung.

Nach Possek gibt es für diese Erscheinung zwei Erklärungsmöglichkeiten: Entweder handelt es sich um das Auftreten von zwei 
differenten Substanzen im Blute, von denen die eine, die Netzhautschädliche, ungehindert ihre Wirkung entfalten kann, während die andere, die Linsen-schädliche, von seiten des eingeführten Linseneiweisses eine spezifische Affinität besteht, dieselbe also neutralisiert wird. Oder es könnte auch dieses Versuchsresultat durch quantitative Verhältnissse herbeigeführt werden.

Man kann wohl Possek in der Ansicht beistimmen, dass linsenspezifische Gifte im Kreislauf selbst von eingeführtem Linseneiweiss aufgefangen werden können und dass so ihre toxische Wirkung ausbleibt.

Aber ich kann nicht, wie Possek, in dieser Tatsache eine Unterstützung der Römerschen Annahme erblicken, denn offenbar ist dieser Umstand nur eine von den Vorbedingungen, die zutreffen müssten, wenn eine von Voraussetzungen, wie es diejenigen Römers sind, veranlasste Therapie Aussicht auf Erfolg geben sollte.

Denn vor allem ist ja der Vergleich des künstlich erzeugten Naphthalinstars mit dem subkapsulären senilen Star, soweit es sich um das Studium der pathologischen Vorgänge in der Linse selbst handelt, durchweg berechtigt und hat zu ungemein wertvollen Resultaten in dieser Richtung geführt. Aber nicht zu übersehen ist, dass Vergleichen in ätiologischer Beziehung wieder dieselben Fehler anhaften müssen, wie dem Vergleich des Altersstars z. B. mit der diabetischen oder tetanischen Katarakt; denn wie bei den letzteren Formen treten auch beim Naphthalinstar schwere Allgemeinerscheinungen auf; auch hier bestehen im Gegensatze zu den einen Altersstar tragenden Individuen Zeichen schwerer Vergiftung, die in starker Abmagerung, Diarrhöen (oft mit massenhaften Darm-Hämorrhagien) und Nierenveränderungen sich äussern (Hess loc. cit. Seite 174).

Nach dem Ausfall des oben geschilderten Possekschen Versuches, seine Richtigkeit vorausgesetzt (Angaben über die Zahl seiner Versuche und über die Konstanz der beobachteten Erscheinungen fehlen; auch ist, wie bekannt, die Wirkung des eingeführten Naphthalins auf die Linse durchaus nicht eine regelmässig eintretende), würde eine solche Therapie bei den erwähnten toxischen Kataraktformen des Menschen, z. B. der tetanischen oder der diabetischen, nicht ganz aussichtslos erscheinen und vielleicht prophylaktisch etwas leisten kömnen.

Eine zweite Vorbedingung für die Wirksamkeit der Lentokalintherapie ist der Nachweis der biologischen Identität der Linsentabletten Römers mit frischen Linsen, $d$. h. der Nachweis, dass die biologischen Eigenschaften der Linse auch dann nicht verloren gehen, 
wenn die frische Tierlinse durch verschiedene Prozeduren in Trockensubstanz übergefuihrt wird. Da Römer bis auf weiteres die Verwendung der nach seiner Angabe hergestellten Linsentabletten nur sich allein vorbehalten hat, so waren wir gezwungen, unsere Versuche mit Tabletten anderer Provenienz auszuführen; dieselben waren von der Firma G. Richter in Budapest so hergestellt worden, dass vollkommen frische Schweinslinsen im Vakuum getrocknet, pulverisiert und dann zu Tabletten gepresst wurden. Eine Tablette entsprach 0,1 der Trockensubstanz.

Diese Tabletten waren im stande, die Hämolyse zu verhindern:

\begin{tabular}{c|c|c|c}
\hline \hline & \multicolumn{3}{c}{ Tablettenextrakt: 3 Tabletten auf 10 NaCl } \\
Tabletten & akt. Menschenserum & Kaninchenblut & Hämolyse \\
\hline 2 & 0,2 & 1 & $\theta$ \\
2 & 0,1 & 1 & $\theta$ \\
2 & - & 1 & $\theta$ \\
$\mathrm{NaCl} 2$ & - & 1 & $\theta$ \\
$" 2$ & 0,2 & 1 & komplett \\
$" 2$ & 0,1 & 1 & $"$,
\end{tabular}

Der Agglutinationsversuch dagegen, in derselben Weise vorgenommen wie bei der frischen Linse, blieb negativ. Die Originaltabletten Römers jedoch, die ich mir später durch gütige Vermittlung Herrn Professors Elschnig in kleiner Anzahl verschaffen konnte, gaben Agglutination, wenn auch schwächer, wie die frische Linse.

Der Versuch mit Tetanolysin konnte nicht angestellt werden, da wir zur Zeit, als uns das Lysin zur Verfügung stand, bereits für andere Versuche alle Tabletten verbraucht hatten.

Wichtiger für den Nachweis der Identität ist eine andere biologische Reaktion in gleicher Weise zur Prüfung aller organ-therapeutischen Präparate geeignet.

Ein Kaninchen erhielt dreimal in $Z$ wischenräumen von fünf Tagen einen Extrakt von je 5 Tabletten in physiologischer Kochsalzlösung subcutan injiziert. Zehn Tage nach der letzten Injektion wurde dem Tier Blut entnommen.

Während das vor der ersten Injektion untersuchte Serum des betreffen. den Kaninchens mit Linse keinen Niedersehlag gegeben hatte, präcipitierte das Tablettenimmunserum ein Tablettenfiltrat ziemlich stark, aber nicht nur dieses, sondern auch in genau gleicher Weise ein Filtrat aus frisehen Schweinslinsen. Dadurch erscheint der Nachweis der biologisehen Gleichwertigkeit beider Filtrate einwandfrei erbracht. 


\begin{tabular}{c|c|c|c}
\hline $\begin{array}{c}\text { Tablettenimmun- } \\
\text { serum }\end{array}$ & Linsenfiltrat & NaCl & $\begin{array}{c}\text { Präcipitation nach } 2 \text { und } \\
24 \text { Stunden }\end{array}$ \\
\hline \hline 0,2 & 0,2 & 0,6 & +++ \\
0,2 & 0,05 & 0,7 & ++ \\
0,2 & 0,01 & 0,7 & + \\
0,2 & 0,001 & 0,7 & $\theta$ \\
0,2 & Tablettenfiltrat & 0,6 & +++ \\
0,2 & 0,2 & 0,7 & ++ \\
0,2 & 0,05 & 0,7 & + \\
0,2 & 0,01 & 0,7 & $\theta$
\end{tabular}

Für die Möglichkeit der Wirkung des Lentokalins ist weiters die Art der Applikation von grosser Bedeutung.

Römer hat dafür die Verabreichung per os gewählt, aus leicht begreiflichen Gründen. Denn, wie bereits einmal erwähnt, hat die, Injektion von Eiweisssubstanz häufig aseptische Eiterungen und auch im hohen Grade die Gefahr der Anaphylaxie zur Folge. , Auch uns gingen zwei Tiere, denen wir Linsenemulsion unter die Haut gespritzt hatten, bei der Wiederholung der Einspritzung rasch ein.

Damit die eingeführte Linsensubstanz ihre paralysierende Wirkung auf die hypothetischen toxischen Produlte entfalte, ist es notwendig, dass sie in den Kreislauf übergeht. Nach ihrer Einverleibung muss sie also auch im Blute nachweisbar sein. Dieser Nachweis ist derzeit auf zwei Arten möglich: durch die Methode der Präcipitation und die Methode der Komplementbindung. - Injiziert man einem Tiere eine Eiweisslösung oder führt man dieselbe intraperitoneal ein (Uhlenhuth), so gewinnt, wie zuerst Tchistowitsch 1899 gefunden hat, das Blutserum die Eigenschaft, mit der betreffenden Eiweisssubstanz und nur mit dieser einen Niederschlag zu geben. Bei der Methode der Komplementrerankerung wird das Komplement unwirksam gemacht, so dass die Hämolyse in einem hämolytischen System ausbleibt.

Aus den oben erwähnten Gründen war es nicht möglich, die Linsensubstanz Menschen zu injizieren. Es wurde daher der Tierversuch gewählt und zwar am Kaninchen, während gleichzeitig Menschen mit grösseren Quanten von Tabletten und frischen Linsen gefüttert wurden.

Dass das Serum des Kaninchens nach Injektion eines Filtrates aus 15 unserer Tabletten sehr stark präcipitierte, erhellt aus dem zuletzt angefülurten Versuch. Dagegen präcipitierte das Serum des Patienten R. (Ablatio retinae), der in Zwischenräumen von '2-3 Tagen je fünf Tabletten, im ganzen 50 per os bekam, und dem acht Tage nach der letzten Fütterung Blut ent- 
nommen wurde, ein Linsenfiltrat auch nielt in Spuren nach einer Beobachtungsdauer von 15 Stunden.

\begin{tabular}{c|c|c|c}
\hline Linsenfiltrat & Serum des Patienten R. & NaCl & Präcipitation \\
\hline $\begin{array}{c}0,5 \\
0,2\end{array}$ & 0,5 & $\overline{0,2}$ & $\theta$ \\
\end{tabular}

Dasselbe Resultat gab das Blutserum des Patienten N. (Atrophia nervi optrci), der in derselben Weise mit je zehn frischen Schweinslinsen, im ganzen 60 an der Zahl, gefüttert worden war und dem acht Tage nach der letzten Darreichung etwas Blut entnommen wurde.

\begin{tabular}{c|c|c|c}
\hline Linsenfiltrat & Serum N. & NaCl & Präcipitation \\
\hline 0,5 & 0,5 & - & $\theta$ \\
0,2 & 0,5 & 0,3 & $\theta$ \\
0,1 & 0,5 & 0,4 & $\theta$ \\
0,01 & 0,5 & 0,5 & $\theta$ \\
0,5 & $-5,5$ & 0,5 & $\theta$ \\
& 0,5 & 0,5
\end{tabular}

Bei diesen Versuchen wurde also Linsensubstanz in Mengen verabreicht, wie sie bei der Medikation Römers auch nicht annähernd so gross und erst in viel längerer Zeit zur Anwendung kommen. Trotzdem war keine Spur von Linsenantikörperbildung im Blute nachweisbar, was voraussetzt, dass die präcipitinogene Substanz der Linse nicht in den Kreislauf gelangt war.

Hervorzuheben ist hier, dass die Methode der Präcipitation eine sehr feine Reaktion darstellt; noch Verdünnungen von 1:10000 geben deutliche Niederschläge.

Nun freilich ist die hier ebenfalls anwendbare Methode der Komplementbindung noch empfindlicher und vermag noch $100 \mathrm{fach}$ so starke Verdünnungen anzuzeigen.

Jedoch konnten wir um so leichter die Anwendung dieser Reaktion unterlassen, als von anderer Seite zahlreiche Untersuchungen vorliegen, die die Unwirksamkeit der Applikation per os klar beweisen.

Es hat freilich Uhlenhuth Präcipitine in dem Serum eines Kaninchens nachweisen können, das mit Hühnereiweiss gefüttert worden war, aber nur nach enormen Mengen und nach 24 tägiger ausschliesslicher Nahrung mit diesem Stoffe, unter Bedingungen also, wie sie praktisch überhaupt nie in Betracht kommen.

Analog ist das Resultat der Versuche von Metschnikoff, der bei Tieren durch Ingestion von Elementen des Organismus Hämolysinbildung erzielen konnte. Doch wird von Bertarelli(22) und Andern dagegen der Einwand erhoben, dass die Antikörperbildung 
nor dann stattfinde, wenn bei der Einführung der Magensonde die Magen- oder Speiseröhrenschleimhaut verletzt wurde.

Tatsächlich scheinen die Versuche Bertarellis diese Ansicht $\mathrm{zu}$ bestätigen.

B. hat bei Kaninchen, denen er in weniger als 15 Tagen mehr als $400 \mathrm{cem}$ Kuhmilch dargereicht hatte, Präcipitation erzielt, stets nur bei Zwangs-(Über-)Ernährung mit heterogener Mileh.

Wenn aber diese Ernährung in langen Pausen ausgeführt wurde, war experimentell keine Antikörperbildung nachweisbar, auch wenn eine solche Behandlung monatelang fortgesetzt wurde. Es tritt also, wie Bertarelli folgert, diese Bildung von Antikörpern nur ein, wenn die normale Funktion der Schleimhaut des Verdauungstractus geschädigt (verändert) wird.

Bei Säuglingen war durch Fütterung mit heterogener Milch keine Präcipitation hervorzurufen.

Damit steht in Einklang, dass von den im Diphtherie- und Tetanusheilserum in Gestalt von genuinem Eiweiss enthaltenen Heilkörpern bei Applikation per os bei Erwachsenen keine Spur in das Blut gelangt, wie Behring (23) nachgewiesen hat. Dagegen fand sich bei Neugeborenen das unveränderte antitoxische Eiweiss bei derselben Applikation im Blute vor.

Ebenso bestätigen Paul H. Römers Versuche, dass erwachsene Individuen aller Tierarten die genuinen Eiweisskörper erst verdauen - in Peptone usw. umwandeln müssen, ehe dieselben die Intestinalschleimhaut passieren können.

Und auch $\mathrm{G}$ an ghofner und Langer (24) haben durch zahlreiche Tierversuche sichergestellt, dass zwar bei Neugeborenen - etwa bis zum 7. Lebenstage - körperfremdes Eiweiss per os eingeführt, als solches zur Resorption gelangt, dass aber bei Erwachsenen ein solcher Übergang niemals festzustellen ist, solange die Zufuhr von Eiweiss die bei den gewöhnlichen Ernährungsverhältnissen etwa in Betracht kommende Menge nicht wesentlich überschritt; nur bei ganz kolossalen Quantitäten war unter Umständen auch beim erwachsenen Tiere Antikörperbildung nachweisbar.

Beim erwachsenen Menschen konnten Ha mburger und Sperk (25) dagegen niemals ein positives Resultat erhalten; diese Autoren kommen auf Grund ihrer zahIreichen Versuche zu der Überzeugung, dass der Durchtritt von unverändertem, artfremdem Eiweiss durch die Wände des Verdauungstractus in die Blutbahn überhaupt ausgeschlossen ist.

Die moderne physiologische Chemie lehrt, dass durch die Tätigkeit der Verdauungsfermente all die komplizierten, unendlich oft in Art und Menge wechselnden Nahrungsstoffe in ihre Bausteine zerlegt

v. Graefe's Archiv für Ophthaimologie. LXXII. 3. 
und dass das Nahrungseiweiss, bevor es in die Blutbahn gelangt, so transformiert wird, dass es seinen ursprünglichen Charakter völlig verliert. Und Abderhalden(26) konnte zeigen, dass die Eiweisskörper des Serums stets gleiche Zusammensetzung zeigen, gleichgültig, ob das zugeführte Eiweiss der Nahrung in seiner Zusammensetzung den Serumeiweisskörpern näher steht oder nicht. „Durch eine solch tiefgehende Aufspaltung der Nahrungsstoffe macht der tierische Organismus die Zellen seiner Gewebe in weitgehendstem Masse von der Art der dem Körper zugeführten Nahrung unabhängig. Nicht Nahrungseiweiss cirkuliert also im Blute, sondern Körpereiweiss; die eingeführte Eiweisssubstanz wird durch weitgehenden Abbau zu arteigener; dann erst vermag sie zur Ernährung der Zelle beizutragen" (Abderhalden loc. cit.).

Aus all dem ergibt sich der zwingende Schluss, dass die per os eingeführte Eiweisssubstanz der Linse in derselben Weise wie jedes Nahrungseiweiss im Magendarmkanal abgebaut wird und lange schon alle spezifischen Eigenschaften verloren haben muss, wenn sie in das Blut gelangt.

Einen interessanten Beitrag zu dieser Frage liefert Börnstein (27) in seinen ebenfalls auf die Katarakttherapie Römers Bezug habenden Untersuchungen, die zur Entdeckung des bisher noch nicht bekannten Bestandes einer "Anaphylaxie durch Fütterung gegenüber Fütterung". gefiubrt haben.

Bei herbivoren Kaninchen war nach längerer Fütterung mit Linsensubstanz regelmässig Antikörper-(Präcipitin-) bildung nachweisbar; nach sehr langer Fütterung (9-16 Wochen) und täglicher Dosis von einer Rinderlinse kam es in den meisten Fällen zu plötzlichem Tode durch typischen anaphylaktischen Shock im Anschluss an die letzte Fütterung.

Bei Untersuchungen an fleischfressenden Katzen, ferner am eigenen Leibe (Börnstein nahm über 11 Wochen täglich eine Rinderlinse) war keine Antikörperbildung nachweisbar, ebenso trat keine Anaphylaxie auf.

Aus diesen Resultaten kann man wohl - glaube ich - ebenfalls den Schluss ziehen, dass beim Fleischfresser die Assimilation des tierischen Eiweisses eine vollständige ist, dass die eingeführte Linseneiweisssubstauz nicht als artfremde, spezifische Eigenschaften besitzende, sondern als arteigene, zu Serumeiweiss umgewandelte Substanz in das Blut gelangt, daher irgendwelcher Toxinbindung im Kreislauf nicht mehr fähig ist. Ich kann aus eben diesem 
Grunde aber nicht so weit gehen, wie es Börnstein tut, der auf Grund dieser Versuche auch beim Menschen die Harmlosigkeit einer dauernden Fütterung mit Linseneiweiss in Frage zu stellen geneigt ist.

Offenbar geht bei Pflanzenfressern, deren Magendarmtrakt auf tierisches Eiweiss nicht eingestellt ist, die Assimilation nicht so weit; hier gelangt (ob nicht auch durch Verletzungen der Schleimbaut beim Einführen der Sonde?) das Linseneiweiss in das Blut; es wirkt dann als Antigen und regt Antikörperbildung an.

Demnach ist es ein ganz bedeutender Unterschied, ob bei der von Römer eingeführten Therapie die direkte Einführung in das Blut oder die Applikation per os gewählt wird. Der letzteren muss von vornherein jede Möglichkeit einer Wirkung abgesprochen werden.

Durch die angeführten Tatsachen erklärt sich auch ganz ungezwungen ein Versuch Posseks (loc. cit.). Wenn einem Kaninchen Naphthalin und Linsensubstanz, zu einem Brei gemengt, mittels Magensonde beigebracht wird, so tritt auf gleiche Art (in vielen Fällen noch rascher und intensiver) wie mit Naphthalin allein gefüttert Star auf. Possek sucht die Erklärung dieses Resultates darin, dass, wie bekannt, nicht das Naphthalin als solches auf die Linse schädigend wirkt, beziehungsweise zur Linse eine spezifische Affinität besitzt, sondern dass es erst im Magendarmkanal zerlegt werden muss; dass ferner das Naphthalin vom Magen aus viel schneller resorbiert wird, als das Linseneiweiss, und daher in der Blutbahn seine umsetzende Wirkung entfalten und auf diesem Wege auf die Linse einwirken kam, bevor noch Linseneiweiss in die Blutbahn gelangt ist.

Ich glaube, dass nur der erste dieser Gründe stichhaltig ist, dass aber der Ausfall dieses Versuches hauptsächlich darauf zurückzuführen ist, dass das Linseneiweiss eben verdaut wird und überhaupt nicht in spezifisch wirksamer Form in das Blut gelangt. Eine kleine Modifikation dieses Versuches in der Weise, dass man zuerst Linsensubstanz in den Magen, nach einigen Stunden erst das Naphthalin einführt, würde gewiss die Richtigkeit dieser Ansicht klar legen können.

Um die bis jetzt von Römer mitgeteilten Erfolge seiner Behandlung beurteilen zu können, müssen wir uns vor allem die Frage stellen: Was können wir, seine Wirksamkeit in der angenommenen Weise vorausgesetzt, von dem Mittel überhaupt erwarten?

Nehmen wir einstweilen mit Römer an, die senile Katarakt entstehe durch Toxinwirkung, so müssen wir in den getrübten Linsen- 
partien Zellkomplexe erblicken, welche bereits eine Bindung mit dem Toxin eingegangen sind. Von diesem Augenblick an sind sie tot, einer Wirkung des eingeführten Heilmittels nicht mehr zugänglicb, um so mehr, als ja dasselbe nur im Blute wirken, gar nicht zur Linse gelangen soll. Es werden also alle weiteren Vorgänge, die sich in diesen Fasern und um sie herum abspielen, rein lokaler Natur sein, unabhängig davon, ob ein wirksames Heilmittel in den Körper eingeführt wird oder nicht.

Nun ist ja derzeit noch nicht mit vollkommener Sicherheit zu entscheiden, ob eine Aufhellung von wirklichen Trübungen der Linsenfasern selbst (die also nicht auf reinen Flüssigkeitsansammlungen zwischen denselben beruhen) bei der senilen Katarakt möglich ist, wenn auch Hess unter Hinweis auf vereinzelte, von guten Beobachtern mitgeteilte Fälle diese Möglichkeit zugibt. Tn allgemeinen aber und in der grössten Zahl der Fälle wäre also ein Stehenbleiben des Zerfalles keine Besserung, dasjenige was wir durch das Mittel selbst erreichen könnten. Da aber die von Römer gebrachten Tabellen über die Resultate mit seinem Mittel - bei subkapsulärer Katarakt - durchwegs von Besserungen berichten, so müssten solche, sonst sicher enorm seltene Aufsaugungen von Startruibungen bei Anwendung des Römerschen Mittels fast zur Regel gehören, wenn man nicht etwa annehmen wollte, dass auch schon die Aufsaugung von Flüssigkeitsansammlungen um die zerfallenen Fasern beim Auflören der schädigenden Einflüsse genügen würde, um eine solche Besserung zu erklären.

Gerade diese ïberraschenden Resultate, nach denen also das Mittel mehr zu leisten scheint, als man von ihm erwarten konnte, weisen darauf hin, dass andere Umstände bei denselben von grosser Bedeutung sind.

Ich will hier auf die Gründe nicht näher eingehen, die solche Besserungen, wie sie Römer beschreibt, auch bei Unwirksamkeit des Mittels erklären könnten. Es ist ja zuzugeben, dass Römer alle diese Massnahmen getroffen hat, die notwendig sind, um solche Fehlerquellen nach Möglichkeit auszuschalten, und nach seinen letzten Mitteilungen (1909) ist er auch weiter bemüht, ein möglichst klares Urteil über diesen Punkt zu gewinnen. $O b$ es aber möglich sein wird, alle die möglichen Täuschungen auszuschliessen, kann wohl mit Recht bezweifelt werden. Bemerken will ich noch, dass auch rom praktisçen Standpunkte das Mittel nicht gerade ein ideales darstellt, denn der Patient muss, wenn die ganze Behandlung nicht 
wertlos sein soll, sein ganzes Leben lang Schweinslinsentabletten zu sich nehmen, eine Art Nahrung, die derzeit noch etwas kostspielig ist.

\section{Zusammenfassung.}

Wenn wir zum Schlusse unsere experimentellen Feststellungen überblicken, so ergibt sich daraus etwa folgendes:

Nachdem der Beweis erbracht schien, dass dieselben haptophoren Gruppen, wie sie normalerweise oder bei Immunisierungsprozessen im Blutserum gelöst vorhanden sind und dort als Antikörper bezeichnet werden, auch in der Linse vorkommen, hat man daraus weitgehende Schlüsse auf die Pathogenese der subkapsulären Form des Altersstars gezogen.

Man ging von der Vorstellung aus, dass im alternden Organismus durch Zellzerfall cytotoxische Produkte entstehen, welche, den durch senile Veränderungen in seiner Retentionsfähigkeit geschädigten Ciliarkörper passierend, mit den nachgewiesenen Receptoren der Linse eine Verbindung eingehen und das Linsenprotoplasma zum Absterben bringen. Wir glauben dagegen gezeigt zu haben, dass, trotzdem wir fast alle Versuchsresultate Römers bestätigen konnten, die Deutung derselben nicht zutrifft, wenn man die Experimente, die zur Aufklärung dieser Frage angestellt wurden, im Sinne der neueren Forschungsergebnisse auf diesem Gebiete erweitert.

I. Zuerst konnten wir nachweisen, dass den in der Linse vorhandenen, Kaninchenblutkörperchen agglutinierenden Stoffen gerade das Hauptmerkmal der von Ehrlich festgestellten Immunkörperreaktion, nämlich die Bindung fehlt. Damit erscheint die Receptorennatur dieser Stoffe ausgeschlossen.

II. Die Fähigkeit der Linse, Tetanolysin zu binden (Receptorentypus I. Ordnung), kommt, wie wir experimentell festgestellt haben, in hohem Grade den alkohollöslichen Stoffen der Linsensubstanz zu; eine Tatsache, die ebenfalls die Receptorennatur ausschliesst, da die Receptoren, wie sie im Serum vorkommen, nicht alkohollöslich, sondern alkoholfällbar sind: Die Linse besitzt keine Receptoren I. Ordnung.

III. Ebenso liegt keine Berechtigung vor, aus der Eigenschaft der Linsensubstanz, Komplement zu binden, auf Receptoren III. Ordnung zu schliessen, da mit allergrösster Wahrscheinlichkeit auch diese komplementbindenden Stoffe den alkohollöslichen angehören und ausserdem vielfach nachgewiesen ist, dass die in den Organzellen vorhan- 
denen wasserlöslichen komplementbindenden Stoffe nicht Receptoren entsprechen; denn bisher ist es niemals gelungen, die an den Zellen etwa vorhandenen fixen Receptoren in Wasser in Lösung zu bringen.

Diese komplementbindenden Stoffe sind vielmehr nicht spezifischer Natur und haben mit den spezifischen Amboceptoren der Körperflüssigkeiten keine Gemeinschaft.

IV. Aus dem Gesagten geht hervor, dass sich im Experimente der Nachweis des Receptorenaufbaues der linse nicht nur nicht begründen, sondern mit grösster Wahrscheinlichkeit widerlegen lässt.

V. Da sich der Nachweis von Antistoften gegen bestimmte Gewebe mittels der Komplementbindung erbringen lässt, so haben wir diese Methode zur Auffindung von gegen die Linse gerichteten Stoffen benutzt.

Dabei zeigte sich, dass schon normalerweise solche Stoffe im Blute rorkommen, dass sie sich im kataraktösen Serum nicht in vermehrtem Masse vorfinden, wohl aber beim Luetiker mit positiver Wassermannscher Reaktion. Hier dürften dieselben mit den komplementbindenden Stoffen, wie sie die Wassermannsche Reaktion nachweist, identisch sein.

Daraus folgt, dass es nicht gelingt, die von Römer supponierten Antistoffe beim starbehafteten Menschen in besonderer Art nachzuweisen.

VI. Um zu untersuchen, ob die Retentionsfähigkeit der sekretorischen Apparate des Auges beim Altersstar aufgehoben ist, haben wir Individuen mit subkapsulärer Alterskatarakt mit einem reichlich Antikörper bildenden Vibrionenstamm immunisiert, konnten aber in keinem Falle Agglutinine oder Bakteriolysine im Kammerwasser nachweisen, während das Blut diese Stoffe in reichstem Masse enthielt. Daraus ergibt sich der Schluss, dass der Ciliarkörper in bezug auf seine Undurchlässigkeit für gewisse Antistoffe beim Starkranken sich genau so verhält wie beim Normalen, so dass cytotoxische Stoffe, selbst wenn sie im Sinne Römers im Blute entstehen würden, gar nicht zur Linse gelangen könnten.

VII. Aber überhaupt erscheint es im höchsten Grade wahrscheinlich, dass die senile Katarakt - und zwar alle Formen derselben - nur eine rein lokale, nicht in Beziehung zum Gesamtorganismus stehende Alterserscheinung darstellt; denn es vermag nur diese Anschauung alle klinischen Erscheinungen dieser Affektion befriedigend $\mathrm{zu}$ erklären. 
VIII. Die Lentokalintherapie Römers betreffend liess sich zeigen, dass per os einverleibte Linsensubstanz weder in frischem noch trockenem Zustande im stande ist, beim Menschen Präcipitine zu erzeugen, was soviel bedentet, dass dieselbe nicht in antigener Form in das Blut gelangt, daher auch nicht Toxin bindend wirken kann, wie es für die therapeutische Wirksamkeit vorausgesetzt werden müsste. Subcutan einverleibt dagegen, erzeugt sowohl die frische als auch die getrocknete Linsensubstanz reichlich Präcipitine.

Demnach erscheint nicht nur die Therapie Römers, sondern auch ihre Voraussetzungen als nicht genügend begründet.

\section{Literaturverzeichnis.}

1) Bouchard, Leçons sur les auto-intoxications dans les maladies (1887) cit. nach Martius, Pathogenese innerer Krankheiten. 1909.

2) r. Jaksch, Die Vergiftungen. Nothnagels spez. Pathologie und Therapie. Bd. I. 1897.

3) Elschnig, Augenerkrankangen dureh Autointoxikation. Klin. Monatsbl. f. Augenheilk. Bd. XLIII, 2. 1905.

4) Fleischmann u. Davidsohn, Über Cytotoxine. Folia serologica. Bd. I, 3. S. 188.1908.

5) Landsteiner u. Donath. Münchner med. Wochenschr. Nr. 36. 1904.

6) Golowin, De l'importance des cytotoxines dans la pathologie oculaire et en particulier dans la pathogénèse de l'inflammation sympathique. Arch. d'opht. XXXV.p. 98.

- Hypothese der autocytotoxischen Entstehung von Augenerkrankungen. Klin. Monatsbl. f. Augenheilk. Februar 1909. \$. 150.

7) Römer, Die Pathogenese der Cataracta senilis rom Standpunkt der Serumforschang. Arch. f. Ophth. Bd. LX. S. 175. 1905. Areh. f. Augenheilk. Bd. LVI. Ergzhft. S. 150. 1907.

8) Wessely, Experimentelles uber subconjunctivale Injektion usw. Klin. Monatsbl. f. Augenheilk. Bd. XL. S. 267 ff. Deutsche med. Wochenschr. 1908. Heft 7 u. 8.

9) Hess, Linse. Graefe-Saemisch Handbuch. Bd. VI. Abt. II.

10) Groenouw, Erbliche Erkrankungen der Linse. Graefe-Saemisch Handbuch. Liefg. $37-38$. S. 430 .

11) Weil, E., Uber den Mechanismus der Bakterienagglutination durch Gelatine. ZentralbI. f. Bakteriol. Bd. XXXVII, 3. 1904.

12) Bang, Ivar, Physiko-chemische Verhältnisse der Blutkörperchen. Biochemische Zeitschr. Bd. XVI, 4 u. 5. 1909.

13) Landsteiner, K. u. Raubitschek, Über Adsorption von Immunstoffen. Biochem. Zeitsehr. Bd XV. S. 32. 1908.

14) Weil u. Braun, Sind in den Organzellen Antikörper nachweisbar? Biochem. Zeitsehr. Bd. XVII, 4.

15) Le ber, A., Untersuchungen über den Stoffwechsel der Krystallinse. v. Graefe's Arch. f. Ophth. 1906.

16) Gross, O., Beiträge zur Linsenchemie. Arch. f. Augenheilk. Bd. LVII. S. 107 .

17) Kuwabara. Arch. f. Augenheilk. Bd. LXIII, 2. S. 121. 1909.

18) Possek, R, Schildarüse und Auge. Klin. Monatsbl. f. Augenheilk. Bd. XLV. Beilageheft. 1907.

- Die Theorien uber die Entstehung der Alterskatarakt. Wiener klin. Wochenschr. Nr. 34. 1908. 
19) Greeff, Linse und Glaskörper. Lehrbuch der spez,-pathol. Anatomie von Orth. 1905. 11. Liefg.

20) Jackson. 55. Jahresvers. der Americ. Medical Assoc. 1898.

21) Possek, R., Lassen sich Linsentrübungen organtherapeutisch beeinflussen? Wien. klin. Wochenschr. Nr. 12. 1909.

22) Bertarelli, Untersuchungen ther die Zubereitung von Koagulinen auf gastrischem Wege. Zentralbl. f. Bakt. Bd. LVIII, 5 .

23) Behring. Deutsche med. Wochenschr. Nr. 39. 1903.

24) Ganghofner u. Langer, Über die Resorption genuiner Eiweisskörper im Magendarmkanal neugeborener Tiere u. Säuglinge. Münchn. med. Wochenschr. Nr. 34. 1904.

25) Hamburger u. Sperk. Wiener klin. Wochenschr. Nr. 23. 1904.

26) Abderhalden. Lehrbuch d. physiol. Chemie. 1906.

27) Börnstein, F., Anaphylaxie durch Fütterung gegenüber Fütterung. ZentralbI. f. Bakteriol. Bd. L, 3. 1909.

28) Schenk, Untersuchungen über das biologische Verhalten des mütterlichen und kindlichen Blutes und über Schutzstoffe der normalen Milch. Monatssehrift f. Geburtshilfe und Gynäkol. Bd. XIX. 1903. 